CUPAUAM 25.1, 1998, pp. 201-243

\title{
SOBRE LA CRONOLOGÍA DE COGOTAS I...
}

\author{
Catalina Galán SAULNIER \\ Universidad Autónoma de Madrid
}

\section{Resumen}

Las dataciones absolutas relacionadas con Cogotas 1 han sido objeto de diferentes analisis e interpretaciones de los que se han derivado trabajos en los que se proponen diversas clasificaciones culturales y cronologicas. Esas diferencias se deben a la diversidad de opiniones al respecto, según distintos investigadores, y a la práctica de diferentes metodologías de trabajo que en ocasiones conllevan la exclusión de determinadas fechas, la combinación de los resultados de las dataciones radiocarbónicas con los obtenidos mediante otros métodos como la tipologia y a diferentes interpretaciones de las circunstancias que rodean a algunas de dichas fechas. A la vista de todo ello, el presente trabajo pretende exponer la situación actual en que se encuentra el problema de la clasificación cronocultural de Cogotas I y plantea una nueva interpretación de los datos disponibles que se plasma en la identificación de Cogotas $I$ como un complejo cultural cuya aparicion, desarrollo y etapa final se escalonaron a lo largo de todo el II milenio a.C. en función, al menos en parte, del desarrollo de acontecimientos geográfica y culturalmente externos.

\section{Summary}

The absolute dates related to "Cogotas $F$ have been object of different analysis and interpretations. Several cultuml and chronological classifications have been created out of those different works. In opinion of some investigators, those differences have their ogigin in the wide variety of opinions existing, in the use of different work methodologies - since this somecimes leads to the exclusion of expecific dates - and also in the use of radiocarbon dating results combined with the results of other methods used such as typology ans interpretation of the circumstances surrounding those dates. Have all this under account, this work tries to point out the current situation of "Cogotas $m$ ' chronocultural classification problem and set up a new interpretation of the available dates, so as the identification of "Cogotas $M$, appearance, develop and final stage developed all among the II Millenium A.D. owing to the develop of the geographical and cultural outward events.

Con cierta frecuencia, quizá demasiada, en la terminología y nomenclanura utilizadas por los prehistoriadores quedan ambiguamente implicitos dos aspectos, intimamente ligados pero a todas luces diferentes, de todo complejo cultural: su identificación y clasificación culturales y su datación concreta, o lo que es lo mismo, la edad de sus restos arqueologicos. 
En otros ambientes cronoculturales mediterráneos y de la Europa Continental, se ha mantenido entre los investigadores una cierta unidad de criterios en este sentido y una especie de acuerdo tácito que, en concreto por lo que respecta a la Edad del Bronce, ha hecho que habitualmente se identifiquen grosso modo grandes periodos históricos con los más representativos complejos culturales de cada uno de ellos, $\mathrm{y}$, en la medida de lo posible, con grandes espacios temporales de límites no demasiado rígidos que, con el tiempo, se han ido modificando en función de la datación, cada vez más precisa, de los restos arqueológicos.

Así, en líneas generales, tradicionalmente se han venido identificando Heládico/Cicládico/Minoico Antiguos con "Bronce Antiguo" y, a su vez, con III milenio A.C., o Cultura de los Túmulos con "Bronce Medio/Pleno" y con II milenio A.C., o Micénico con "Bronce Reciente" y con segunda mitad del II milenio A.C., sin perjuicio de que las dataciones "absolutas", cuyo grado de fiabilidad no parece tan absoluto como en un principio se creyó -y prueba de ello son las revisiones y ajustes a que casi continuamente están siendo sometidas-, obliguen a los investigadores a modificar cada cierto tiempo, en mayor o menor medida, los hitos temporales que indican, o parecen hacerlo, el inicio, desarrollo, apogeo y fin de los respectivos complejos culturales que caracterizan cada una de esas épocas.

Sin embargo, en nuestro país las cosas nunca han estado tan "claras", ni entre los prehistoriadores ha habido un "consenso" tan compartido, y esto incluso desde bastante antes de que las dataciones "absolutas" se empezasen a considerar como un dato arqueologico más; y si a ello se suma "la leña" que en las últimas décadas ha supuesto para este "fuego" el cambio de tendencias en los planteamientos metodológicos y la sustitución de los criterios apoyados en que gran parte de lo que aparece en la Península Ibérica tenía su origen fuera de ella, y en consecuencia habia que "dar tiempo para que llegase", por otros partidarios de buscar un indigenismo en algunos casos hay que decir que "a ultranza" para la mayor parte posible de los elementos que configuran nuestra Prehistoria, no extrañe si hay que admitir que el panorama cronocultural de nuestra Edad del Bronce resulta actualmente bastante confuso, especialmente para quien intente obtener una visión de conjunto de la correlación cronológica entre las distintas áreas -geográficas y/o culturales- de la Península Iberica, como bien ha señalado recientemente $M$. Almagro-Gorbea (1996).

En efecto, hasta hace relativamente poco tiempo, El Argar o el Bronce Valenciano eran sinónimo de "Bronce Pleno/Medio" y grosso modo también de II milenio A.C., y la presencia de cerámica excisa, típica de los grupos europeos de la Culura de Los Túmulos, si en su area de origen representaba el Bronce Medio, aquí, habiendo llegado como consecuencia del movimiento de esas gentes en la última etapa de su cultura, era considerada ya como representativa de un Bronce Final o incluso de los comienzos de la Edad del Hierro $\mathrm{y}$, en consecuencia, temporalmente situable en los últimos anos del II milenio y los primeros del I milenio A.C..

Así, en opinión del propio M. Almagro-Gorbea (op. cit., pág.153), la insuficiencia de información y secuencias estratigráficas bien conocidas en todas las regiones peninsulares obliga a la extrapolación de los datos de la cultura de El Argar y del Bronce Atlántico y a utilizar las dataciones obtenidas del C-14 para reconocer seriaciones locales y correlaciones 
no siempre suficientemente apoyadas en los materiales arqueológicos, su secuencia tipológica y su posición estratigráfica, tal y como sería deseable.

Pues bien, en este marco, más empírico que real, había evidentes dificultades para sinar "aquello" que por no ser claramente argárico o Bronce Valenciano, o por no tener cerámica excisa o determinados tipos metălicos del Bronce Atlántico, no se podia identificar sin problemas como Bronce Pleno/Medio o como Bronce Final, respectivamente, y así empezaron a aparecer en la bibliografia multitud de yacimientos y materiales arqueológicos clasificados simplemente como pertenecientes a la Edad del Bronce, en muchos casos sólo porque no eran claramente ni calcolíticos ni de la Edad del Hierro, todo lo cual no hace sino confirmar el diagnóstico del Prof. Almagro-Gorbea al señalar la compleja articulación interna de la Edad del Bronce peninsular, consecuencia de su configuración y posición geográficas y de la confluencia de tres corrientes culturales, atlántica, mediterránea y ultrapirenaica, sobre substratos también culturalmente distintos (op. cit., pág. 154).

Y en ese mismo marco se fue perfilando también lo que se denominó "horizonte" Cogotas I, que sin duda alcanzaba el final de la Edad del Bronce por la presencia de diferentes elementos así clasificados en función de criterios tipológicos, especialmente en lo referente a los materiales metálicos (Pereira Sieso, 1994; Almagro- Gorbea, 1996), pero cuyo comienzo parecía remontarse cada vez más en el tiempo, primero por las características de algunas de sus cerámicas, y luego por las dataciones "absolutas" con que poco a poco se fueron acompañando éstas.

Así las cosas, los reciente trabajo de Castro, Lull y Micó (1996) y Fernández - Posse (1998) recogen excelentes síntesis, confeccionadas con enfoques diferentes, de lo que se podría definir como "la evolución" de la clasificación cronocultural de Cogotas I, ofreciendo con ello claras exposiciones de la problemática que plantea en este sentido el complejo cultural así denominado tradicionalmente, problemática que, sin embargo, no parece ser tan preocupante para otros investigadores como J.L. Maya y J.S. Mestres (1996), para quienes Cogotas I representa claramente el Bronce Medio-Tardío, o como el propio M. AlmagroGorbea, para quien Cogotas $I^{\mathrm{n}}{ }^{n}$... costituisce l'orizzonte più importante di cronología relativa del Bronzo Recente/Finale della Penisola Iberica ..." (1996, pág. 157), opinión compartida parcial y recientemente por $M^{a} \quad C$. Blasco Bosqued (1997) y más recientemente aún por J. J. Eiroa (2000, pág. 254-255).

\section{PROBLEMAS DE HOY ...}

Si de lo expuesto se deduce que la cronología -en el sentido literal del término, utilizándolo ahora como el estudio de la dimensión temporal- de Cogotas I es uno de los aspectos de la Edad del Bronce de La Meseta que más ha preocupado a muchos investigadores en los últimos tiempos, cabe señalar así mismo que de los trabajos citados -y de otros en los que, de una u otra forma, se siguen criterios semejantes- se desprende también algo que no sólo no contribuye a solucionar el problema, sino que por el contrario más bien parece agravarlo, y es el hecho de que las opiniones sobre qué argumentos deben consi- 
derarse válidos para determinar la posición cronológica de Cogotas I, si los derivados de las dataciones absolutas obtenidas por diversos métodos (C-14, termoluminiscencia) o los obtenidos en función de la cronología relativa, se hallan sensiblemente divididas.

$Y$ es que realmente no es para menos, habida cuenta de que aparentemente de la opción que se escoja depende que Cogotas I represente la fase media o la fase final de la Edad del Bronce del área central de la Península lbérica, ya que en la actualidad sólo excepcionalmente algunos investigadores plantean nuevas denominaciones, señalando que Cogotas I representa la fase de expansión de la Edad del Bronce -obviando así el uso de la terminologia tradicional- entre 1750 y 1250 a.C. y desde la Meseta hacia su periferia, al menos hacia el valle del Ebro (HARRISON, 1995), o solucionan la situación con otras interpretaciones, tales como que "... en la Meseta el Bronce Medio y Final están caracterizados por la cultura de Cogotas I, liegando a través de lo ceitiberico hasta lo celtibérico-romano, hacia el año 100 a.C.; ..." (Moure y Santos, 1999, pág. 71), por no mencionar el caso de aquéllos que proponen clasificaciones cronoculturales partiendo de unas dataciones absolutas que previamente han seleccionado por considerarlas no "discordantes con el contexto", no "contradictorias" y "concordantes" con las de complejos culturales "bien conocidos", o lo que es lo mismo, que han escogido por ajustadas a las clasificaciones más tradicionales (Maya y Mestres, op. cit.).

En honor a la verdad hay que admitir que uno de los problemas latentes tras esa "división de opiniones", si no el fundamental, es el mismo que a lo largo del último tercio del s. XX ha sido, junto a la renovación de los planteamientos metodológicos, una de las principales causas de los cambios que se han ido observando en la interpretación y reconstrucción de la Prehistoria peninsular, y es que la utilización de los resultados obtenidos de la aplicación a la Arqueología de las, en cada momento, "nuevas tecnologías", no siempre lleva a las conclusiones establecidas con la metodología tradicional, sin que ello implique ni que la Arqueometría proporcione sistemáticamente datos definitivos que supongan la solución de los muchos problemas que la Prehistoria tiene aún por resolver, ni que los métodos tradicionales de la Arqueología, y entre ellos los que permiten obtener cronologias relativas, constituyan la única vía de solución aceptable para dichos problemas.

Es más, la Prehistoria es Historia, si se quiere "Paleohistoria", y como tal necesita obviamente todo el apoyo que puedan ofrecerle los métodos y técnicas que permitan obtener dataciones puntuales, no tanto en el sentido temporal (puesto que ni las técnicas más precisas proporcionan en realidad fechas totalmente absolutas to que permiten es situar las muestras en periodos más o menos cortos de tiempo, si bien con un grado de aproximación a la realidad cada vez más alto-), como en sentido espacial, puesto que esas dataciones son las de "algo" que se ha localizado en un lugar concreto y que se ha conservado en unas circunstancias que permiten medir su edad.

Esto es cierto, pero no lo es menos que la historia de un lugar no es sino una mínima parte de la Historia y que, salvo que se tratase de un extraño caso de aislamiento total, ese lugar, ese yacimiento arqueológico, conservará con toda seguridad los testimonios de la vida de un grupo humano que pudo ser un simple "grano de arena" o una gran "montaña ${ }^{n}$, pero, en cualquier caso, un elemento constitutivo del "paisaje" histórico conformado por ellos mismos y sus contemporáneos, de tal forma que para reconstruir su historia es 
preciso integrar esos testimonios en el marco temporal que le corresponde, situándolos como sucesores de sus antepasados directos y en relación, al menos temporal, con sus contemporáneos.

Con todo, a nadie escapa que, aun teniendo en cuenta las premisas inherentes a la utilización de los métodos de cronología relativa, si éstos son los que en definitiva permiten reconstruir panoramas históricos generales, también son métodos ciertamente peligrosos en tanto que, al fin y al cabo, son eso, relativos, es decir, se basan en las relaciones (estratigráficas, tipologicas...) que el arqueólogo sea capaz de identificar entre unos testimonios culturales y otros, sin que ello implique necesariamente el conocimiento real de la situación temporal del primer eslabon de esas cadenas.

Estas son las causas de que en el caso concreto de Cogotas I se observe actualmente un gran conflicto respecto a su cronología, puesto que si por una parte varios de sus restos arqueológicos permiten identificar sus relaciones con determinados complejos culturales de datación bien conocida (o al menos aceptada actualmente por una gran mayoría de investigadores), por otra algunos de sus restos permiten situarlos en espacios temporales diferentes a los marcados por esas dataciones, y ésta es a su vez la razón de que el trabajo ya mencionado de Castro, Lull y Mico (1996) haya supuesto una importante aportación a la investigación de la Prehistoria de la Meseta Central española, puesto que saca a la palestra nuevos problemas al revisar las dataciones absolutas existentes, calibrarlas y hacer un verdadero estudio de los hitos temporales conocidos de dicho complejo, es decir, al exponer su cronología determinando los límites de su aparición, desarrollo y desaparición e identificando una serie de "inflexiones" en la serie de fechas que llevan a los autores no sólo a exponer los datos y los problemas que éstos plantean, sino también su interpretación de ambos aspectos, ahondando más en su cronologia y en la propia diferenciación entre "horizonte" y "cultura" de Cogotas 1 , que en su correspondencia con una época histórica determinada, es decir, con un periodo concreto de la Edad del Bronce.

Pero si en algún caso la bibliografia especializada permite constatar hasta qué punto la Arqueología es una ciencia "viva", este es un buen ejemplo de ello, ya que el último aspecto citado del trabajo de Castro, Lull y Micó ha sido matizado prácticamente de inmediato por $\mathrm{M}^{2} \mathrm{C}$. Blasco Bosqued en una nueva aportación a la problemática de Cogotas $I$ en la que la autora, utilizando los datos recogidos y elaborados por el equipo catalán y aportando otras informaciones y enfoques, no solo delimita el marco cronologico del "horizonte $^{n}$ Cogotas $I$, sino que determina sus diferentes fases y establece su correspondencia con la periodización "clásica", tradicional o más comúnmente utilizada, de la Edad del Bronce (Blasco Bosqued, 1997).

\section{LOS DATOS MÁS CONCRETOS}

La realidad que se desprende de las líneas precedentes es que, pese a ser "un tema de actualidad" en el panorama de la Prehistoria reciente peninsular, hoy por hoy Cogotas $I$ sigue siendo una manifestación arqueológica de algo cuya verdadera entidad (igrupo?, ¿cultura?, ¿complejo cultural?, ¿"horizonte"?) no ha sido aún claramente identificada, y ello debido en buena parte al hecho de que su cronología es "cambiante" y discutida atendiendo a 
las diferentes opiniones de los estudiosos del tema, y como consecuencia, también lo es su clasificación cronocultural.

Es evidente que las interpretaciones que de los datos arqueologicos puedan hacer diferentes investigadores siempre podrán ser discutibles, pero también lo es que algunos de esos datos son más concretos que otros, y algunos lo son de tal manera que en sí mismos no pueden ser cuestionados.

En este sentido, fuera cual fuera el "estatus cultural" de quienes hoy son conocidos como "las gentes de Cogotas $I$ ", y correspondiesen a unas u otras fases de ese periodo histórico que convencionalmente se denomina Edad del Bronce, hoy son obvios datos como que sabían fabricar cerámica o que inhumaban a algunos de sus muertos, pero también lo es que en algunos niveles arqueológicos formados con los restos de su ocupación de algunos lugares, hay restos $-\mathrm{y}$ ya en una cantidad si no definitiva al menos sí suficientemente indicativa- que, en función de las ciencias y tecnologías al uso, denotan tener una edad que sólo será discutible en la medida que se discuta la validez de la aplicación de éstas.

Evidentemente la edad cientifica y objetivamente medida de esos restos arqueológicos no debe ser un dato a discutir sino a constatar y utilizar, con toda la precaución que requiere el ser conscientes de que tal vez en el futuro el desarrollo tecnológico obligue a modificar los valores de algunos de esos datos. Ahora bien, hay que reconocer que en realidad al arqueólogo no le interesa tanto el valor numérico, en este caso la edad concreta de un resto fechado, como el uso que pueda hacer de su presencia en un determinado lugar y en un determinado contexto, puesto que el arqueólogo utiliza las dataciones como un elemento más que, junto a otros, le permite "identificar situaciones", compararlas, establecer secuencias y, en definitiva, interpretar los restos culturales y las circunstancias de su presencia para reconstruir las correspondientes parcelas de la historia de quienes tuvieron relación con ellos.

Este es el motivo de que, en el estado actual de la investigación sobre Cogotas I, resulte enormemente atractivo ahondar en la problemática de su cronología, y más concretamente de las dataciones absolutas que si para algunos investigadores suponen las bases más sólidas en que apoyar la interpretación de ese "fenómeno" cultural, para otros no son sino datos demasiado específicos, puntuales, poco fiables y, sobre todo, distorsionadores del aparentemente sólido esquema de clasificación cultural establecido en base a otros métodos de datación tradicionalmente aceptados por la comunidad científica, como es, en el caso concreto que nos ocupa, la tipología de los objetos metálicos.

Desde esta óptica es evidente la importancia del ya varias veces mencionado trabajo de Castro, Lull y Mico y obligada la referencia al mismo en tanto que supone un muy completo corpus de dataciones absolutas calibradas relacionadas con Cogotas $I$-al que apenas hay que sumar alguna más como las de Hoyas del Castillo en Pajaroncillo, Cuenca (Ulreich, Negrete y Puch, 1994) y la del yacimiento madrileño del Caserio de Perales (Blasco y otros, 1995)-, y sobre todo no solo por la novedad que ha supuesto el "envejecimiento" de las fechas con que se había venido confeccionando su marco temporal, -novedad que más bien tiene una importancia relativa, puesto que las calibraciones no suponen más que modificar los límites superior e inferior de dicho marco-, sino, sobre todo, porque 
esas calibraciones han proporcionado ciertas "sorpresas" que, en algunos casos, han llevado a los autores a prescindir de determinadas fechas aun cuando sus interpretaciones se refieren al conjunto.

A fin de facilitar aquí la exposición de este específico lote de datos, en la Tabla 1 se recogen las dataciones estudiadas por Castro, Lull y Mico, junto a la procedencia y "circunstancias" que las acompañan, indicándose las que en opinión de los autores (op.cit;; 161) conforman la serie vâlida de fechas radiocarbónicas procedentes de yacimientos en los que, de una u otra forma, se ha detectado la presencia del "horizonte" Cogotas I y que, en cronología calibrada, abarca desde c. 2050 a c. $600 \mathrm{ANE}$, o lo que es lo mismo, todo el II milenio A.C. y buena parte del I. A partir de ese conjunto de fechas, los autores abordan los problemas que algunas de ellas plantean señalando los aspectos que a continuación se indican.

\section{Extensiónde.la_secuencia}

La serie se extiende entre $c .2050$ y $c .600 \mathrm{cal}$. ANE, pero según los extremos del rango interdilicio, los límites se establecen entre 1680 y $1020 \mathrm{cal}$. ANE, por lo que se pueden excluir aquellas dataciones "desajustadas" que se sitúan en el $\mathfrak{I}$ milenio (Fábrica de Ladrillos, Bouça do Frade) o que superan la fecha de $c .1800 \mathrm{cal}$. ANE (Castelho Velho, Setefilla, Peñalosa, Arevalillo de Cega), en ambos casos por tratarse de fechas "... claramente distanciadas de la serie general y probablemente alteradas por problemas de registro o postdeposicionales. De este modo las cerámicas decoradas pueden situarse a lo largo de una diacronía de unos 700 años, entre c. 1700 - 1000 cal. ANE..." (Castro, Lull y Mico, op. cit.; 161).

\section{Disimetría de la serie}

En los yacimientos con dataciones "operativas" se observa la disimetria cronológica que se desprende del hecho de que:

- sólo algunos se sitúan en el s. XVII a.C. (El Cogote, Los Tolmos, La Corvera),

- Arevalillo, La Plaza y La Venta se ubican en el s. XVI a.C.,

- Moncín, Gatas y Cuesta del Negro tienen fechas que se extienden hasta el s. XIV,

- Llanete de los Moros, Atapuerca, Ecce Homo, La Venta y La Requejada muestran cronologías más recientes, y

- La Requejada, Cueva de Los Espinos, Atapuerca y la Fábrica de Ladrillos son más tardíos y ya cercanos al 1000 cal. ANE. 


\begin{tabular}{|c|c|c|c|}
\hline $\begin{array}{ll}3 \\
3\end{array}$ & M. & (1) & 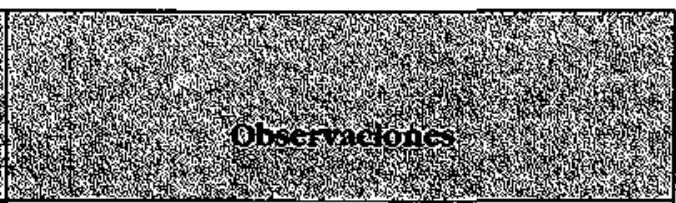 \\
\hline & & 2080 & $\begin{array}{l}\text { Nivel de babitación ladera baja. Carbon. Viga o poste. } \\
\text { Excluida por "desafustada" }\end{array}$ \\
\hline IA AN & Perialosa & 2042 & Idem. Carbsn. Idem. Idem. \\
\hline JAEN & & 1750 & $\begin{array}{l}\text { Nivel de abandono valler ladera supertior Carbon. Viga o } \\
\text { poste. }\end{array}$ \\
\hline & & 1690 & Nicel abandono cima cerro. Cátion. Yiga o poste. \\
\hline BUTRGOS & El Portalon & 2034 & Carbon. Excluida por "desajustada" \\
\hline & (Atapuerca) & 1704 & Carbont. \\
\hline & Nivel III & 1455 & Carbon. \\
\hline & & 1017 & Cantosn. \\
\hline & & 1986 & $\begin{array}{l}\text { Fase II B. Corte } 1 \text { Nierel } 11 \text {. Mezcla de grano y ramitas. } \\
\text { Exclusida por "desofustada". }\end{array}$ \\
\hline & & 1952 & $\begin{array}{l}\text { Fase II B. Nivel II. Mexcla de grano y ramiuas. Excluida por } \\
\text { "desajustada". }\end{array}$ \\
\hline & & $\overline{1648}$ & Fase I D. Nitel 4. Belloras. \\
\hline & & 1630 & $\begin{array}{l}\text { Periodo II. Nivel 7. Fase II C. Reacon-dicionamiento } \\
\text { asemtamiento pre-Cogotas I Cortón. }\end{array}$ \\
\hline ZARAGOZA & Moncin & 1590 & Foyo F3. Fase II B. Carbon. \\
\hline & & 1581 & Hoyo. Fase II A. Cartion. \\
\hline & (Pase II) & 1550 & Nitel 3. Periodo $\bar{I}$. Primenas centimicas Cogatas $\bar{J}$. Carbon. \\
\hline & & 1510 & Fooso F2. Fase $\bar{I}$ B. Cartón. \\
\hline & & 1435 & Hoyo F3. Fase $\Omega$ B. Carton. \\
\hline & & 1370 & 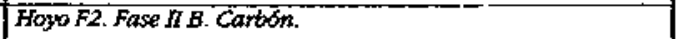 \\
\hline & & 1345 & Cuadro IA $I D$. Nivel 4. Cotageno. \\
\hline & & 1332 & Fase II A. Noel 2 a. Hogar casa pledra. Carbón. \\
\hline & & 1310 & Cundro 1. Nivel III A. Colegeno. \\
\hline PORTTKAY & Castellureltho & 1920 & Carbon. Excluida "por prudencia" \\
\hline & (Estrato I) & $\mathbf{1 1 1 7}$ & Carbisn. Exchida por ajena al contexto. Intruston moderna. \\
\hline & 10 & 1860 & Hogar Carbbri. Exchukda Fecha ojena a serie contexto \\
\hline SEGOVA & de Ceosa & 1581 & Cereal en silo. \\
\hline & 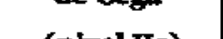 & 1581 & Hogar 4. Cartion. \\
\hline & (nvelia) & 1576 & Junto a Hogar i.Cereal. \\
\hline SEVIILA & Setefilla & 1859 & $\begin{array}{l}\text { Estrato XIV. Nivel de derrumbe. Carbón. Exclusda por } \\
\text { 'desafustada:. }\end{array}$ \\
\hline & & 1799 & Estrato $X V V y$ XIII base. Idem. Carbon. Idem. \\
\hline fyo & F) Conote & 1716 & Fosa 4. Cañon. \\
\hline siven & wis ale & 1650 & Fosa 11. Carbón. \\
\hline & Ins Tolmos & 1682 & Relaclonada con las inbumactones. Cartion. \\
\hline & 200 A a & 1676 & Nivell I. Carbón. \\
\hline SORA & & 1668 & Nitei II. Cartabn. \\
\hline & & 1466 & $\begin{array}{l}\text { Nivel } \overline{I I . ~ C a r b o n . ~ C e r d m i c a ~ e x c i s a . ~ E x c l u t d a ~ p o r ~ s u t ~} \\
\text { distanciamtento de ta serte. }\end{array}$ \\
\hline & & 1295 & Nhel h. Carbón. Exclutida por su distanciamiento de la serie. \\
\hline SATAMANCA & Ia Corvera & 1655 & Cartion. \\
\hline & & 1587 & Carbon. \\
\hline
\end{tabular}

Tabla 1. Cronologia de Cogotas / según Castro, Luil y Mico, 1996 (en negrita: dataciones vátidas según los autores) 


\begin{tabular}{|c|c|c|c|}
\hline PROVINGA & YAOIMMENTO & $\begin{array}{l}\text { Datacion } \\
\text { C14 cal } \\
\text { ANE m }\end{array}$ & Observactones \\
\hline \multirow{2}{*}{ PAIENCIA } & \multirow{2}{*}{ La Venta } & 1583 & Fomo boyo 65, base. Cartion. \\
\hline & & 1382 & $\begin{array}{l}\text { Homo boyo } 65 . \text { Garbon. Nivel sobre demimbe. Excluida por } \\
\text { proceder de nivel de abandono solme derrumbe. }\end{array}$ \\
\hline \multirow{3}{*}{ PORTUGAL } & \multirow{3}{*}{$\begin{array}{l}\text { Tapado de } \\
\text { Caldeira }\end{array}$} & $\mathbf{3 5 7 8}$ & Sep. I, nicel de base. Carbon. \\
\hline & & 1489 & Sep.1. Carbinn. \\
\hline & & 1228 & Estratio 28. Cantesn. \\
\hline VALLADOUD & La Plaza & 1560 & Carbon. \\
\hline \multirow{5}{*}{ ALMERfA } & \multirow{5}{*}{ Gatas } & 1540 & Semillas. \\
\hline & & 1524 & Con boquilque Semillas. \\
\hline & & 1469 & Ceneal. \\
\hline & & 1378 & Cańbin. \\
\hline & & 1362 & Carbsn. \\
\hline \multirow{3}{*}{ GRANADA } & \multirow{3}{*}{$\begin{array}{l}\text { Cuesta del } \\
\text { Negro } \\
\text { (Estrato VI) }\end{array}$} & 1466 & Nivel de incendio. Carbon. \\
\hline & & 1455 & Tdem. Excisa Carbón. \\
\hline & & $\mathbf{1 3 8 0}$ & Nixel de habitaciôn. Carbon. \\
\hline VALLADOLID & Boecillo & 1460 & Carbonn. \\
\hline ALAVA & $\begin{array}{c}\text { Txabola de la } \\
\text { Hechicera }\end{array}$ & 1455 & Intrustion en lümulo sep. de comedor. Cartón. \\
\hline \multirow[t]{2}{*}{ PALENCIA } & \multirow{2}{*}{$\begin{array}{l}\begin{array}{l}\text { C. Los Espinos } \\
\text { (nivel II) }\end{array} \\
\end{array}$} & 1398 & Carbón. \\
\hline & & 1003 & $\cos b \sin$. \\
\hline \multirow{3}{*}{ MADRID } & \multirow{3}{*}{ Ecce Homo } & 1384 & HOSO 2/6. Carton. \\
\hline & & 1270 & Hoyos $I / 1$ y $W / 1$ y Hoyo 38. Carbon. \\
\hline & & 1243 & Hojo 24. Carbón. \\
\hline \multirow{6}{*}{ CORDOBA } & \multirow{6}{*}{$\begin{array}{l}\text { Lanete de los } \\
\text { Moros }\end{array}$} & 1354 & Post estrato int. Carbsn. \\
\hline & & 1343 & Estrato DI. Carbón. \\
\hline & & 1305 & Idem. Carbón. \\
\hline & & 1250 & Past. estrato VIII. Semullas. \\
\hline & & 1215 & Estrato Il A. Carbón. \\
\hline & & 1135 & Estrato VI. Carbón. \\
\hline \multirow{2}{*}{ VALLADOLID } & \multirow{2}{*}{ La Requejada } & 1192 & Hogar. Cartion. \\
\hline & & 1035 & Hutusas individuo infantil inbumación $n^{\circ} 3$. \\
\hline ALAVA & $\begin{array}{l}\text { Ia Paul de } \\
\text { Arbigano }\end{array}$ & 1114 & Hoyt. Huesos fauna. \\
\hline \multirow{2}{*}{ MADRID } & \multirow{2}{*}{$\begin{array}{l}\text { Fabrica de } \\
\text { ladrillos }\end{array}$} & 1018 & Misma fecba de C-14 y $\pi$ \\
\hline & & 618 & $\begin{array}{l}\text { Cenizas interior vasija (élincinerarción?). Exclutida por } \\
\text { "desajustada". }\end{array}$ \\
\hline \multirow{2}{*}{ PORTUGAL } & \multirow{2}{*}{$\begin{array}{l}\text { Bouga do } \\
\text { Brade }\end{array}$} & 871 & Cartón. Idem. \\
\hline & & 1243 & Fogo 24. Carbon. \\
\hline
\end{tabular}

Tabla 1. Cronología de Cogotas / segün Castro, Liull y Mico, 1996 (en negrita: dataciones válidas según los autores) 


\section{PROBLEMAS DE LOS YACTMTENTOS}

Pues bien, antes de comentar el tratamiento a que han sido sometidas las dataciones por Castro, Lull y Mico , tratamiento que ha sido criticado por Fernández - Posse (1998) en lo que respecta a la elección del valor de la mediana del intervalo de la calibración a un sigma y en cuanto a la distribución de probabilidades, y antes también de comentar las interpretaciones que los propios autores hacen de los resultados obtenidos, es necesario prestar atención a la propia "situación" de algunas fechas de algunos yacimientos, en ocasiones también comentadas por otros investigadores.

\section{Petalosa (Jaén): callbraciones y contextos.}

En el caso de este yacimiento andaluz, atendiendo a las razones argumentadas por Castro, Lull y Micó (op. cit.), deben obviarse las dataciones de 2080 y 2042 cal. ANE $m$. por sobrepasar el "tope" de $1800 \mathrm{cal}$. ANE, pese a que su contexto(nivel de habitación) pare. ce claro.

Pues bien, asi mismo parece evidente que el hecho de que esas fechas sobrepasen, y nada menos que en más de 200 años, un límite cronológico fijado en función de criterios matemáticos, no es razón suficiente para no tenerlas en cuenta, a menos que efectivamente se hayan producido deficiencias en el registro arqueológico o procesos postdeposicionales no bien detectados, o al menos no publicados.

No obstante, sí es cuestionable la validez de estas dataciones en relación con otras del yacimiento, por una parte porque han sido sometidas a distintos métodos de corrección, tal y como los propios autores indican en el apéndice VI de su trabajo, y por otra porque proceden de elementos constructivos de madera que pudieron haber sido reutilizados o corresponder a estructuras levantadas antes de la aparición de cerámicas de tipo Cogotas $I$ en el yacimiento.

En otro orden de cosas, los investigadores catalanes señalan que las dataciones de 1750 y $1690 \mathrm{cal}$. ANE se asocian a cerâmicas "proto-Cogotas $T^{\text {" }}$, ya que "... formaban parte de los ajuares domésticos del último momento del asentamiento argárico (...) c. 1750-1700 cal. ANE (...) Con ello obtendríamos una datación equiparable a la de las cerámicas de la Meseta Norte (...). No obstante serán necesarias dataciones de muestras de vida corta asociadas a estas primeras cerámicas decoradas meseteñas para confirmar su presencia en contextos argáricos recientes del s. XVII cal. ANE ..." (op. cit; 163).

Todo parece pues indicar que los autores consideran válidas las dataciones citadas, pese a que parece logico pensar que si corresponden a un nivel de abandono estarian indicando el final de una etapa, no su principio, y también pese a que al proceder de elementos arquitectónicos pueden plantear los mismos problemas que las anteriormente citadas. No obstante, los propios autores consideran necesaria su confirmación -requisito que, en ese caso habría que pedir para todas las dataciones conocidas-, al parecer más por resultar ciertamente elevadas respecto a algunas de la Meseta -ya que testimoniarían la presencia de 
estos materiales en el área andaluza en la segunda mitad del s. XVIII A.C., no un siglo antes-, que porque realmente planteen problemas per se en el yacimiento jienense.

\section{El Portalón, nivel III (Atapuerca Burgos): jun problema estratigrafico?}

Las razones expuestas por los investigadores catalanes para la no consideración de la fecha $2034 \mathrm{cal}$. ANE de este yacimiento burgales son las mismas que las señaladas para las más aitas de Peñalosa, por lo que lo argumentado aqui respecto a aquéllas es aplicable a éstas, y a lo antes expresado hay que añadir que dicha fecha corresponde tanto al nivel III del yacimiento, como las otras 3 dataciones, consideradas sin embargo como válidas por Castro, Lull y Mico quienes, por otra parte, no señalan en el Apéndice VI de su obra razón alguna para su exclusión, y que bien podrían indicar una larga duración para la etapa del yacimiento representada por dicho nivel III.

\section{Moncin (Zaragoza): un caso complejo}

Respecto a las fechas de 1986 y 1952 cal. ANE, Castro, Lull y Micó señalan (op. cit., Apéndice VI) que no resultan válidas por corresponder a una mezcla de grano y ramitas, pero las excluyen también por sobrepasar el $1800 \mathrm{cal}$. ANE, pese a que, como se recoge en la Tabla 1, corresponden a la Fase IIB del yacimiento igual que otras admitidas por los autores y de cronología efectivamente más reciente.

En cuanto al tratamiento dado por los investigadores catalanes a dichas dataciones, cabe señalar que:

- Obviamente los argumentos aplicables a la exclusión de fechas por rebasar el "tope" propuesto son los mismos que en los casos anteriores.

- No obstante, es cierto que en el caso de este yacimiento no parece demasiado clara la relación fases-periodos-niveles, pues de los datos recogidos se desprende que:

- la fase más antigua y de más amplia duración sería la Fase IIB, cuya extensión vendría determinada, en principio, por las fechas de c. 1986 y $c .1952$ cal. ANE (nivel 1), c. 1590 y c. 1435 cal. ANE (hoyo F3) y c. 1510 y c. 1370 cal. ANE (hoyo F2);

- las fases II/D y II/C, representadas por las fechas $c 1648$ y c. $1630 \mathrm{cal}$. ANE (niveles 4 y 7 , respectivamente), corresponderían pues a sendos "interestadios" en la fase anterior (IIB: $c .1986$ - c. $1370 \mathrm{cal}$. ANE);

- la fase IIA, representada a su vez por las fechas de $c$. 1581 y c. $1332 \mathrm{cal}$. ANE, se solaparían temporalmente con la última etapa de la Fase IIB, cuya secuencia de dataciones era, como se ha indicado, c. 1986 - c. 1952 - c. 1590 - c 1550 - c. 1435 - c. 1370 cal. ANE

- En cualquier caso, todo parece indicar que el panorama que ofrecen las dataciones absolutas del yacimiento aragonés resulta demasiado problemático (Tabla 5) como para 
solamente dar por válida la fecha de $1550 \mathrm{cal}$. ANE asociada a la aparición de las primeras cerámicas Cogotas $I$, a menos que el denominado Periodo/Fase II tenga una dilatada duración y un contexto con un alto grado de homogeneidad, suficiente para indicar que se trata de una sola fase de la ocupación del lugar en la que, en un determinado momento aparecen esas cerámicas decoradas.

- Por otra parte cabe señalar que esto es lo que podría desprenderse de la afirmación de Castro, Lull y Micó sobre la constatación en el yacimiento aragonés de "... un reacondicionamiento del asentamiento preCogotas I en tomo a 1630 cal. ANE .." (op. cit., pág.164), lo que lleva a considerar esa fecha como final de la fase "preCogotas" - posible comienzo de la fase Cogotas $I$, salvo en el caso, aparentemente poco probable, de que dicho reacondicionamiento fuese obra de algún grupo de ocupantes del lugar posteriores a los "precogotianos" y anteriores a los de Cogotas I

\section{Castelho Velho (Portugal): prudencia y estratigrafia}

Respecto a la única fecha disponible al parecer de este yacimiento portugués, $c .1920$ cal. ANE, Castro, Lull y Micó señalan su no consideración por las mismas razones anteriormente citadas -sobrepasar el "tope" de $1800 \mathrm{cal}$. ANE-, pero además también por "prudencia" y como "dudosa" (op. cit; ; 162), aunque no especifican los problemas concretos que plantea el contexto de que procede, argumentando de nuevo la posibilidad de que se hayan producido deficiencias en el registro arqueologico o problemas derivados de procesos postdeposicionales.

El resultado final es pues la desestimación de una datación de nuevo extrameseteña, en este caso la única del yacimiento portugués, y de nuevo más elevada que las más altas -procedentes todas éstas de la Submeseta Norte- que los autores consideran válidas, datación que curiosamente procede del mismo estrato que ha proporcionado la fecha de c.1117 cal ANE, desestimada por los autores por corresponder a una intrusión "moderna" en un contexto anterior, todo lo cual inclina a pensar que posiblemente ambas dataciones tengan mucho que ver con una temprana aparición en el área portuguesa de elementos característicos del II milenio a.C. de La Meseta, y tal vez también de la etapa siguiente.

\section{Cueva de Arevalillo de Cega (Segovia): fechas y decoraciones cerámicas}

Curiosamente Castro, Lull y Micó desestiman, también por "prudencia" y como "dudosa" (op. cit.; 162), así como por las razones expuestas para otras dataciones superiores a $1800 \mathrm{cal}$. ANE, la fecha de $1860 \mathrm{cal}$. ANE, procedente de una muestra que, en principio, no debe plantear problemas respecto a su validez, puesto que los propios autores no lo han hecho constar en el ya citado Apéndice VI de su trabajo.

Dicha fecha procede del mismo nivel IIa del yacimiento que las otras dos dataciones consideradas sin embargo válidas, motivos éstos que obligan a tener muy en cuenta dicha fecha de $1860 \mathrm{cal}$. ANE de esta cueva, por otra parte no tan alejada del supuesto límite de c. 1800 cal. ANE, y especialmente representativa entre las que hoy arrojan luz sobre el 
panorama cronológico de todo lo relacionado con las cerámicas tipo Cogotas $I$, entre otras razones porque, en base a la información publicada se trata de una interesante fecha asociada tanto a la perduración de las decoraciones incisas, tan íntimamente ligadas al vaso campaniforme, como a la "reaparición" de la técnica de boquique, en tanto que dicha datación se ha asociado no sólo a un nivel arqueológico en el que aparecen vasos cerámicos decorados con una y otra técnicas, sino incluso a alguna producción cerámica en la que ambas, incisión y boquique, comparten espacio en un mismo vaso (Fernández-Posse, 1981, fig. $\left.6, n^{\circ} 17\right)$ que, además, presenta una disposición y composición de su decoración -a base de un tema radial que cubre la mayor parte de su superficie exterior- que desde luego es mâs fácil relacionar con los diseños campaniformes, pese a incluir motivos hechos a boquique, que con las bandas y metopas dispuestas horizontalmente en la zona superior de los vasos decorados que caracterizan a Cogotas I.

En este sentido, cabe señalar que precisamente en este caso y especialmente por la presencia de ese ejemplar cerámico, resulta obvia la coexistencia en un mismo tiempo y espacio de las tradiciones técnicas campaniforme y Cogotas I, por "extraña" que resulte a algunos investigadores, aunque parece que además se convierte en verdaderamente "molesta" si se asocia a la mencionada datación de c. 1860 cal. ANE, ya que:

- Castro, Lull y Micó desestiman dicha fecha por las razones señaladas;

- Blasco, Calle y Sánchez-Capilla plantean que en Arevalillo se hallan "... materiales adscribibles a la fase ProtoCogotas $I$, aunque asociados tanto a elementos propios de Cogotas de plenitud como al horizonte campaniforme, (...) Sin embargo estas asociaciones deben ser manejadas con cuidado ya que podríamos encontrarnos ante niveles con materiales procedentes de ocupaciones distintas que no llegaron a formar acumulaciones estratigráficas y, en consecuencia, no es posible diferenciar los elementos de cada uno de los asentamientos." (Blasco, Calle y Sánchez-Capilla, 1995, pág. 93), interpretación que no deja de resultar sorprendente pues difícilmente se puede deducir la existencia de restos de oculpación de dos grupos cultural y temporalmente diferenciados ante la presencia de un solo vaso cerámico con las técnicas decorativas propias de ambos;

- más recientemente $\mathrm{M}^{2} \mathrm{C}$. Blasco Bosqued no incluye ninguna de las dataciones del yacimiento segoviano en la serie asociada al vaso campaniforme porque "... las cerámicas campaniformes se asocian a las típicas de Cogotas $I^{n}$ (1997, pág. 62, nota 2), al tiempo que excluye la fecha de $c .1860 \mathrm{cal}$. ANE de las series asociadas a Cogotas I sin explicar el motivo, incluyendo sin embargo las dos dataciones más recientes - c. 1581 y c. $1576 \mathrm{cal}$. ANE en la serie correspondiente a la etapa de formación de dicho "horizonte" (op. cit., Tabla 3) pese a que, según la autora, la decoración de boquique no aparece hasta la etapa de plenitud, ya en el último cuarto del s. XIII a.C.

\section{Setefilla (Sevilla): cerámicas en niveles de derrumbe ...}

Este interesante yacimiento ha proporcionado dos dataciones, 1859 y $1799 \mathrm{cal}$. ANE, de alguna forma relacionadas con la presencia de cerámiças tipo Cogotas $I$ en el Valle del Guadalquivir y procedentes de niveles de derrumbe, pero sin que las muestras correspon- 
dientes planteen problemas per se, o al menos éstos no han sido mencionados por Castro, Lull y Micó en el Apéndice VI de su obra.

Respecto a dichas cerámicas decoradas, Ios autores senalan que "... aparecían entre los niveles de derrumbe de estructuras de donde proceden las dos muestras datadas $C$. 1850-1800 cal. ANE (...) que podrían fechar la construcción de las estructuras desarticuladas del Bronce Pleno." (op. cit.; 163). Pues bien, en este sentido cabe comentar que esas fechas de 1859 y 1799 cal. ANE, o no plantean problema alguno para ser aceptadas como válidas -salvo, de nuevo, el hecho de que a priori puedan suponer una mayor antigüedad respecto a las meseteñas previamente consideradas como válidas-, 0 , si lo plantean, es un problema puramente arqueologico, ya que:

- si proceden de un estrato/nivel revuelto, evidentemente su relación con las cerámicas decoradas puede ser inexistente, pero, en ese caso, deberían figurar como explicitamente excluidas por esa razón en la tabla de dataciones que Castro, Lull y Micó presentan a modo de apéndice de su trabajo, de la misma manera que se ha indicado en otros casos; por el contrario,

- si esas cerámicas decoradas estaban "entre los derrumbes" e inmersas en los tapiales de las "estructuras desarticuladas del Bronce Pleno", y los carbones que han proporcionado esas dataciones proceden del derrumbe de esas mismas estructuras, entonces:

- dichas fechas pueden datar la construcción de esas estructuras, o bien las cerámicas incluidas en los tapiales si carbones y cerámicas estaban asociados cuando se levantaron los correspondientes alzados, pero también es posible que

- las cerámicas, evidentemente anteriores a las construcciones en cuyo tapial quedaron inmersas, sean anteriores a su vez a dichos carbones o incluso algo posteriores a los mismos pero, en cualquier caso, de fabricación previa a la de las estructuras clasificadas como correspondientes al Bronce Pleno.

\section{Los Tolmos (Soria); dataciones y enterramientos}

En el caso de este yacimiento, tomado como paradigma del "horizonte" Cogotas I por la mayoría de los investigadores, al parecer las fechas obtenidas hasta el momento no plantean problema alguno respecto a su inclusión en la serie de dataciones válidas, pero sí merece especial atención sin embargo la más elevada, c. $1682 \mathrm{cal}$. ANE, que, procedente de una muestra de carbón, se ha asociado a la inhumación triple localizada en el yacimiento. Se trata, como es sabido, de una inhumación en una fosa excavada en niveles con restos de habitación, lo que hace que esté abierta la posibilidad de que dicha fecha no corresponda realmente al enterramiento, sino a los niveles en que se abrio la fosa de la sepultura que, de haber sido asi, correspondería por tanto a un momento posterior.

\section{La Venta (Palencia): ¿datación de un abandono?}

Pese a las reservas con que, en principio, deben analizarse las dataciones procedentes de niveles correspondientes al abandono de los asentamientos, ya comentadas en el caso de Peñalosa, las cuales no implican su exclusión automática de una serie "operati- 
val ya que pueden estar indicando el final de un determinado periodo de ocupación de los mismos, no es fácil sin embargo comprender totalmente los motivos que llevan a Castro, Lull y Mic 6 a plantear que "... también podría considerarse insuficientemente asegurada la datación del nivel formado sobre el derrumbe de la estructura de combustión del hoyo $G$ $5 \mathrm{E}$ de la Venta (...) nivel de abandono que habría que relacionar con el final del asentamiento." (op. cit.; pág. 162).

Por otra parte y con respecto a las dataciones obtenidas para este yacimiento palentino (c. 1583 y c. 1382 cal. ANE), tampoco resultan de fácil comprensión las matizaciones de Blasco, Calle y Sánchez-Capilla, (1995) cuando, señalando de antemano la carencia de datos suficientes para afirmarlo, sugieren que la distancia entre esas dos fechas sólo se explicaría como consecuencia de un dilatado proceso en el relleno de la fosa, ya que:

- o bien se refieren a lo mismo que los investigadores catalanes, es decir, a la difícil interpretación de un relleno arqueológico de formación discontinua, consecuencia de un periodo de utilización de la estructura seguido de un periodo aparentemente de abandono de ese uso en el que, en algún momento, dicha estructura se relleno, intencionadamente o no, con restos de un derrumbe para volver a utilizarse en una etapa posterior, y en este caso la distancia cronológica que señalan esas dos fechas entre dos momentos, uno anterior $\mathrm{y}$ otro posterior al mencionado derrumbe, no parece inaceptable, o bien

- si plantean la posibilidad de que la formación del relleno de dicha estructura se hubiese producido como consecuencia de un proceso de utilización continua, entonces habría que deducir que ese proceso duró nada menos que unos 200 años, lo cual, en principio, resultaria cuanto menos difícilmente aceptable -serían demasiados años sin que el conjunto sufriese alteraciones-, aunque siempre dejando abierta la posibilidad de que pudiera tratarse de un caso excepcional.

Así mismo tampoco parece tan evidente como las autoras proponen la relación entre esas dataciones de La Venta, que de alguna forma indican la utilización del lugar entre los primeros años del s. XVI A.C. y el primer cuarto del s. XIV A.C., y la obtenida para el Caserío de Perales (Madrid), yacimiento cuya datación calibrada (1629 cal. B.C.) lo sitúa a finales del s. XVII A.C., lo que podría indicar la presencia de cerámicas tipo Cogotas I unos 50 años antes en el valle del Tajo que en el asentamiento palentino.

\section{Llanete de Los Moros (Córdoba): una "microserie" problemática}

Las dataciones relacionadas con la presencia de cerámicas tipo Cogotas I en el yacimiento cordobés, utilizadas por Castro, Lull y Micó como referente para la aparición de las mismas en el Valle del Guadalquivir, deben tomarse con ciertas reservas relativas a su significado en los contextos en que se encuentran y, en consecuencia a su posición estratigráfica, dado que:

- atendiendo a las observaciones señaladas por los propios autores, las fechas de 1354 y $1250 \mathrm{cal}$. ANE no parecen proceder de muestras con una posición estratigráfica demasiado clara, en tanto que solamente se indica su posterioridad al estrato VIII del yacimiento por su relación con estructuras que cortan dicho estrato, lo que a la vista de la data- 
ción obtenida para el estrato VI (1135 cal. ANE), nos lleva a pensar en su posible correspondencia al estrato intermedio, es decir, al estrato VII, pero

- la fecha tomada por los autores como tope final de la serie, 1135 cal. ANE corresponde efectivamente, según se recoge en el apéndice final de su trabajo, al estrato VI del yacimiento, lo que resulta sorprendente dado que estratos y niveles de formación posterior -III $\mathrm{B}$, III $\mathrm{A}-$ han proporcionado sin embargo dataciones más antiguas (c. 1215 y c. 1155 cal. ANE, respectivamente).

Todo ello conduce a la observación de que, a tenor de esas dataciones, lo que en realidad proporciona el yacimiento cordobés es solamente una serie de fechas indicativa únicamente de la presencia en algunos de los estratos posteriores al estrato VII del mismo de cerámicas tipo Cogotas I al menos desde $c .1354$ cal. ANE y hasta la segunda mitad del s. XII cal. ANE.

\section{La Requejada (Valladolid): la opinión del excavador}

De la información publicada se desprende que la relàción existente entre las dataciones obtenidas para este yacimiento y las cerámicas decoradas del mismo resulta ciertamente problemática, puesto que las fechas de 1192 y $1035 \mathrm{cal}$. ANE proceden, respectivamente, de un hogar y huesos de un individuo, correspondientes ambos a un enterramiento triple efectuado en el interior de un "hoyo" en cuyo relleno previo se hallaban dichas cerámicas, de todo lo cual se desprende a su vez la muy posible anterioridad de las cerámicas tipo Cogotas I respecto a dicho enterramiento.

Además, y al margen de esta circunstancia, no deja de resultar extraño el hecho de que ambas dataciones sean consideradas por Castro, Lull y Micó como "información cronométrica operativa" -en terminología propia de los autores- cuando el propio excavador señalo, respecto a las fechas de C-14 ya antes de su calibración, que "... se trata de dos fechas no exentas de problemas - en principio las dos se refieren, pese a los 140 años que las separan, a un mismo acontecimiento, y cuentan ambas, por otra parte, con una amplísima desviación standard (+ 150 y 90 respectivamente) ..." (Delibes,1990, pág. 70, nota 9).

\section{La Fábrica de Ladrillos (Madrid) y Bouça do Frade (Portugal): ¿dataciones demasia- do recientes?}

Respecto a las dataciones de $c .618$ y 871 y $866 \mathrm{cal}$. ANE, respectivamente, procedentes de estos yacimientos, en concordancia con lo expuesto anteriormente cabe señalar que su desestimación por el mero hecho de rebasar el "tope" cronológico del año $1000 \mathrm{cal}$. ANE, tal y como proponen Castro, Lull y Mico, resulta un argumento tan difícilmente sostenible como el de la exclusión de las dataciones superiores a $1800 \mathrm{cal}$. ANE por superar un límite establecido en función de criterios matemáticos, siempre efectivamente salvo en el caso de que se trate de fechas erroneamente asociadas al contexto arqueologico con el que se las relaciona como consecuencia de deficiencias de registro o de alteraciones debidas a procesos postdeposicionales. 
Es más, cabe señalar así mismo que si se acepta como válida la datación de c. 1035 cal. ANE de La Requejada, o incluso la de c. 1003 cal. ANE de la Cueva de Los Espinos, obviamente debe aceptarse también la intermedia de $c 1018 \mathrm{cal}$. ANE de La Fábrica de Ladrillos, pues, en definitiva, todas ellas no indicarian sino la existencia de Cogotas $I$ en los últimos años del II milenio a.C., al mismo tiempo que es dificil argumentar la inviabilidad de una larga perduración de los contactos regulares entre La Meseta española y el Norte de Portugal cuando todo parece indicar que existieron ya a mediados del II milenio a.C., tal y como indica la presencia de cerámicas de tipo Cogotas I en Tapado de Caldeira, la necrópolis correspondiente al asentamiento de Bouça do Frade (Alarçao,1990).

\section{LA INTERPRETACION DE LOS DATOS}

Parece pues bastante evidente la complejidada de la cronología de los restos arqueológicos de las gentes que en el II milenio a.C. poblaron buena parte de la Meseta, teniendo en cuenta todas las dataciones disponibles actualmente ( $\mathrm{y}$ aunque a las recogidas por Castro, Lull y Mico se añadan otras conocidas más recientemente, como la de Carrelasvegas (Martín Carbajo y otros, 1993), Hoyas del Castillo o Caserío de Perales del Kío (Blasco, Calle y Sánchez-Capilla, 1995), el panorama no cambiaría), incluso eliminando las más extremas, pero resulta también bastante obvio que esa cronología no es menos compleja si solamente se excluye alguna de dichas dataciones, de tal manera que, en cualquier caso, el panorama que ofrecen los resultados cronométricos se presta a interpretaciones muy diferente en una y otra situación.

Respecto a los argumentos esgrimidos por Castro, Lull y Micó para la no consideración de determinadas dataciones, y reconociendo que, en el estado actual de la investigación, no resulta fácil interpretar las superiores a $1800 \mathrm{cal}$. ANE, y menos aún si proceden de yacimientos alejados de las zonas medias de las cuencas del Duero y el Tajo, parece sin embargo que son ya demasiadas como para no tenerlas en cuenta.

La Arqueometría es una parte de la Arqueología que puede ayudar sobremanera al esclarecimiento de determinados problemas, pero en modo alguno el arqueólogo puede supeditar totalmente la reconstrucción de la Historia a la aplicación de los métodos y técnicas de trabajo de las Ciencias Exactas, como tampoco es científicamente correcto señalar sistemáticamente como posible causa de la presencia de unos datos que, al menos aparentemente, no "encajan" en las hipotesis tradicionales -0 que resultan "incómodos" (Fernández-Posse, 1998) para el planteamiento de otras-, posibles errores en el trabajo de otros investigadores que hayan dado lugar a un incorrecto registro de la información arqueológica y/o a la no detección de la existencia de posibles procesos postdeposicionales que podrían haber alterado los correspondientes yacimientos.

Y es que, como se sugirió en páginas anteriores, el problema que plantea todo ello no estriba solamente en que, a la luz de las dataciones calibradas, resulte más o menos antigua la aparición de las cerámicas tipo Cogotas $I$ y su pervivencia sea más o menos larga, sino que además, de las fechas que se tomen como válidas depende la identificación cul- 
tural de las etapas o fases que sin duda se sucedieron en un proceso de alrededor de un milenio de duración y, en definitiva, la interpretación de su propia presencia y su relación con un "horizonte", "complejo" o "fenómeno" cultural.

Así, utilizando las dataciones que Castro Lull y Mico proponen como válidas, el panorama cronológico asociado a las cerámicas de tipo Cogotas I sería el recogido en la Tabla 2, observándose efectivamente en él la ya mencionada "disimetría cronológica" que señalan los autores en base a los grupos de yacimientos que ellos mismos identifican :

- con inicio anterior a 1600 cal. ANE (El Cogote, Los Tolmos y La Corvera),

- ubicados en el s. XVI cal. ANE (Moncín, Gatas y Cuesta del Negro),

- con cronología más reciente (Llanete de los Moros, Ecce Homo, Atapuerca, La Venta y la Requejada), y

- tardíos (La Requejada, Cueva de los Espinos, Atapuerca y La Fábrica de Ladrillos).

No obstante cabe observar al respecto, por una parte que el segundo de esos grupos debería incluir también la primera mitad del s. XV a.C. si se incluye la fecha de $c .1466$ cal. ANE de La Cuesta del Negro (Granada), en cuyo caso habría que "trasvasar" a ese segundo grupo El Portalón de Atapuerca (Burgos) con su datación de c. 1455 cal. ANE, y por otra que el yaci-

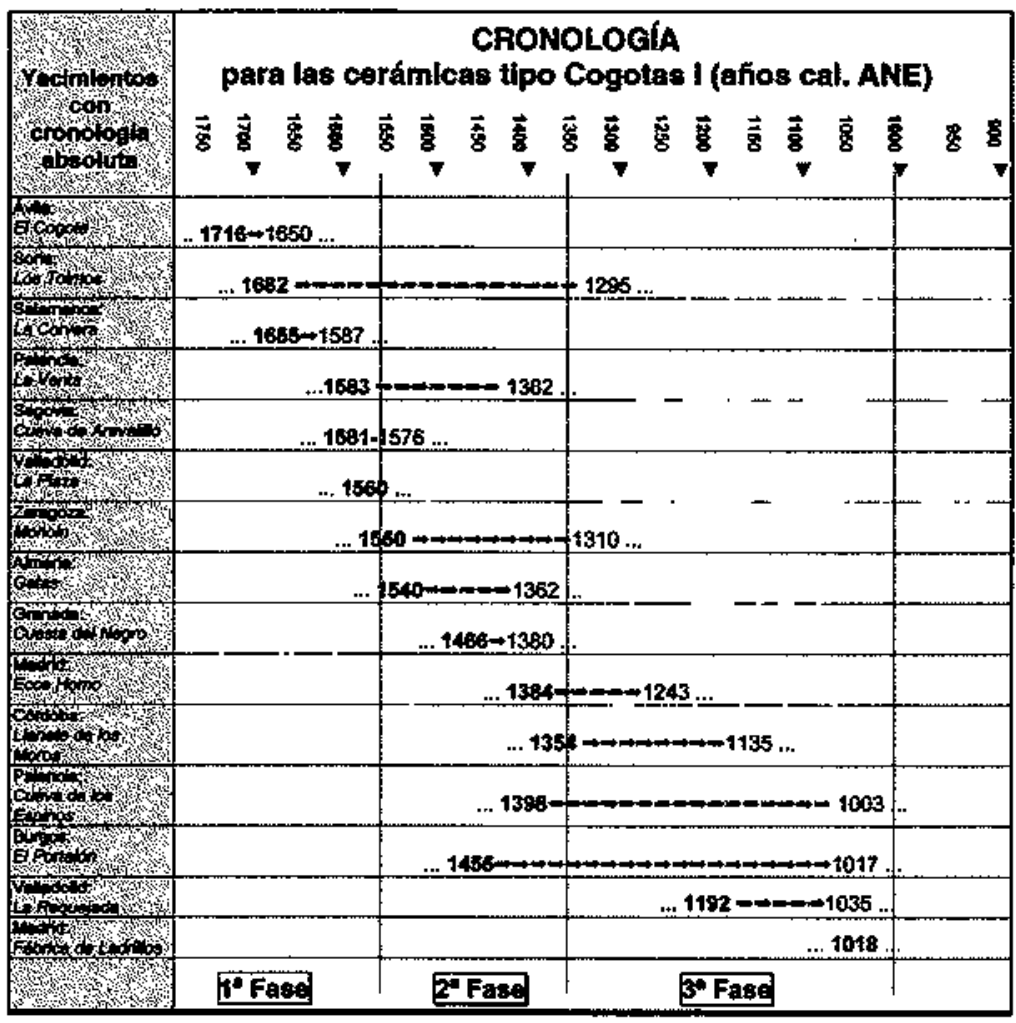
miento palentino de La Venta puede ubicarse en ese tercer grupo sólo si se acepta la propuesta de los propios autores, antes comentada, de obviar su datación más antigua.

En cualquier caso, el resultado del tratamiento dado por Castro, Lull y Micó a las fechas relacionadas con Cogotas $I$ permitiría identificar claramente:

Tabla 2. Según Castro, Llull y Mico, 1996. 
- la presencia de cerámicas de tipo Cogotas $I$ en la zona central de la cuenca del Duero en la primera mitad del II milenio A.C. y antes que en ninguna otra área peninsular, en base a las fechas de los yacimientos del primer grupo;

- la "expansión" de dichas cerámicas hacia la periferia oriental y suroriental de La Meseta ya desde finales de esa primera etapa, en función de las fechas de Moncín y Gatas;

- la "pervivencia" de las mismas en el área central de La Meseta y la continuidad de su "expansión", pero ahora hacia el norte de la propia Meseta y hacia el sur hasta el valle del Guadalquivir, pasando por el del Tajo, a lo largo de la segunda mitad del II milenio A.C. y en base a las fechas de los yacimientos de La Requejada, Atapuerca, Llanete de los Moros y Ecce Homo respectivamente; y por último

- la perduración de la cerámica de tipo Cogotas I en La Meseta, desde el norte de Burgos hasta la cuenca del Tajo, a comienzos del I milenio A.C., como parecen indicar las fechas de La Requejada y la Cueva de los Espinos, Atapuerca y la Fábrica de Ladrillos, respectivamente.

Ante esa selección de dataciones realizada por Castro, Lull y Mico, es pues relativamente fácil observar cómo "...se configuran varias etapas disociadas en el tiempo y que sugieren presencias geográficamente diferenciadas en cada momento ..." (op.cit.; pág. 161), tal y como los autores indican señalando que la distribución de frecuencias permite detectar dos inflexiones en la fasificación de esas cerámicas de Cogotas I, inflexiones que, consideradas como momentos de cambio, informan sobre transformaciones en la dinámica del grupo; dichos cambios habrian tenido lugar $c .1550$ y c. $1350 \mathrm{cal}$. ANE -como se ha reflejado en la citada Tabla 2- y señalarian la existencia de tres fases o etapas:

FASE 1: 1850 - $1550 \mathrm{cal}$. ANE

FASE 2: 1550 - 1350 cal. ANE

FASE 3: $1350-1000 \mathrm{cal}$. ANE

Ahora bien, Castro, Lull y Micó matizan a continuación los límites de ese marco cronológico y de esa periodización con una serie de argumentos no muy fácilmente comprensibles, ya que no se apoyan tanto en los datos arqueológicos que suponen las dataciones calibradas como en una serie de interpretaciones derivadas del tratamiento de la información que realmente proporcionan, y que suponen un conjunto de planteamientos e hipótesis que merecen un detenido análisis y comentario, habida cuenta además de que dichas propuestas difieren, total o parcialmente, de las publicadas también recientemente por otros investigadores (Almagro-Gorbea, op. cit.; Maya y Mestres, op.cit.; Blasco Bosqued, 1977). 
Pese a lo antes expuesto, los investigadores catalanes rebajan hasta $c .1700 \mathrm{cal}$. ANE la fecha del comienzo de una primera fase para la que apuntan una posible correspondencia con lo que se ha venido identificando como Proto-Cogotas I, señalando que de los yacimientos adscritos a ese "horizonte", localizados en los valles del Duero, Tajo y alto Ebro, solamente los de Los Tolmos, Arevalillo, La Plaza, El Cogote, Ca Corvera y La Venta poseen fechas radiocarbónicas "operativas", proporcionando una serie con El Cogote (1716 cal. ANE) y los Tolmos (1668 cal. ANE) en su extremo superior.

Segín Castro, Lull y Mico, la estructura de esa serie indica:

- que el rango interdilícico se ubica $c .1700$ y $1400 \mathrm{cal}$. ANE, por lo que

- no se consideran fechas más altas (Castelho Velho: $c .1920$ cal. ANE; Arevalillo: $c$ $1860 \mathrm{cal}$. ANE) por "prudencia" y dudosas, como ya se comentó, y

- tampoco las más recientes de Los Tolmos (c. 1466 cal. ANE y c. 1295 cal. ANE), por estar asociadas a una cerámica excisa considerada de estilo reciente, la más antigua, y ante la posibilidad de que corresponda a un momento avanzado o final del asentamiento, en el caso de la más reciente (op.cit.; 162). Así,

- el "momento" Cogotas I en Los Tolmos se situaría pues entre 1700 y 1550 cal. ANE, y esta segunda fecha ". sería la cronología más segura para la fase inicial del Estilo Cogotas $I$ y, por ende, de la Cultura Cogotas $I$ en la Meseta, mientras que la fecha 1475 cal. ANE de Los Tolmos (...) dataría una fase posterior con decoraciones excisas." (op.cit., 162).

Tras esa "depuración" de las dataciones absolutas que afectan a la Meseta -lo que incluye también la no consideración de la fecha más elevada del yacimiento palentino de Ia Venta-, Castro, Lull y Micó elaboran la información cronométrica que puede situar las cerámicas de tipo Cogotas $I$ localizadas en yacimientos extrameseteños en momentos anteriores a la mitad del s. XV a.C. y, excluyendo -con reservas- las dataciones de Peñalosa y Setefilla, por las razones ya expuestas, interpretan la presencia de boquique en Gatas en torno a $1525 \mathrm{cal}$. ANE como un referente que permite establecer un paralelismo temporal para la aparición de los elementos de origen meseteño en otros puntos del SE peninsular, en base al hecho de que en Cuesta del Negro "... la fecha de construcción de la unidad habitacional del estrato VI/S, superpuesto a los anteriores y donde ya se constatan decoraciones excisas, data de c. $1450 \mathrm{cal}$. ANE, por lo que los niveles con cerámica encuadrables entre las variantes Proto-Cogotas $I$ deben considerarse anteriotes a este momento y sincronicos a las de Gatas." (op.cit., 163).

Según los autores resulta pues aceptable la identificacion de una primera fase para Cogotas I fechada en c. $1700-1550 \mathrm{cal}$. ANE, abarcando por tanto todo el s. XVI A.C. y prácticamente la primera mitad del s. XVI A.C., y caracterizada por:

* sus cerámicas incisas con decoraciones incisas e impresas de espigas y zig-zags y guirnaldas de semicírculos de boquique, y por

- la extensión de esas cerámicas decoradas por los valles del Duero (Los Tolmos, Arevalillo, La Plaza, Castelho Velho), Tajo (Perales del Río) y sóle posiblemente Guadalquivir (Penalosa, Setefilla) durante el S. XVI cal ANE. 
Evidentemente este análisis tan selectivo de las más antiguas fechas relacionadas con las cerámicas tipo Cogotas $I$ lleva a Castro, Lull y Micó a unas conclusiones que, al menos en parte, no hacen sino confirmar algunas de las más tradicionales hipótesis referidas a Cogotas $I$, puesto que los autores afirman finalmente que las dataciones apoyan su origen meseteño y su posterior expansión hacia las regiones periféricas, si bien antes de su momento de apogeo.

Sobre la Fase 2: c. $1550-$ c. 1350 cal. ANE

Si para Castro, Lull y Micó las dataciones anteriores a c. 1550 cal ANE y actualmente "operativas" señalan la aparición y primer desarrollo de Cogotas $I$ a lo largo del s. XVII A.C. y en la Meseta Norte, las dataciones "válidas" situadas entre esa fecha y mediados del s.XTV A.C. indican to siguiente:

- las fechas de c. 1550 cal. ANE de Moncín, c. 1578 cal. ANE de Tapado de Caldeira y c. 1540 cal. ANE de Gatas, representan la aparición de cerámicas de tipo Cogotas $I$ en el alto Ebro, la zona del bajo Duero y el SE respectivamente, en torno a $1550 \mathrm{cal}$. ANE;

- la fecha de c. 1354 cal. ANE de Llanete de Los Moros indica que fue después de c. 1400 cal. ANE cuando tuvo lugar su aparición en el bajo Guadalquivir y también en el valle del Tajo, puesto que, dado que las relaciones entre la Meseta $\mathrm{N}$ y el SE debieron "pasar" por el valle del Tajo, es posible que los yacimientos de esa zona cubran el intervalo s. XVII-s. XIV cal. ANE, respectivamente.

Así pues, en opinión de los investigadores catalanes, la segunda fase de Cogotas $I$ se caracterizaría por:

- la aparición de las cerámicas tipo Cogotas I fuera de la Submeseta Norte.y por tanto de su área de origen, en base a

* su presencia a partir de c. 1550 - 1500 cal. ANE en el alto Ebro y SE (Moncín, Cuesta del Negro, Cerro de La Encina, Fuente Álamo, Gatas), yąen una segunda época en la que el repertorio decorativo se vería enriquecido son la incorporación de la cerámica excisa.

Pues bien, respecto a las fechas utilizadas para determinar los límites cronológicos de esta segunda fase de Cogotas $I$, cabe señalar a la vista de todo ello que esta interpretación de las fechas calibradas propuesta por los investigadores catalanes parece también algo "enfocada" hacia la confirmación de hipotesis previamente planteadas, de tal forma que su aceptación depende, por una parte de la exclusión definitiva de ciertas dataciones conocidas, exclusion que, como se ha apuntado en otro lugar, es discutible, y por otra de que se incorporen o no a la serie de fechas utilizables las publicadas con posterioridad a su trabajo.

Este planteamiento deriva de la observación de que tomar la fecha de c. $1550 \mathrm{cal}$. ANE de Moncín como indicativa del comienzo de esta segunda etapa supone tomar como representativa una datación intermedia entre otras muy próximas (c.1578 de Tapado de 
Caldeira) y $c .1540$ cal. ANE de Gatas), tal vez porque aceptar la más antigua de ellas como indicador cronológico supondría a su vez aceptar que la presencia de cerámicas de tipo Cogotas I en el bajo Duero, ya en tierras portuguesas, se produjo con anterioridad a su aparición en el Valle del Ebro.

Así mismo, no resulta fácilmente comprensible cómo una fecha que en un determinado momento "se sacrifica" en función de la utilización de otra -media entre dos valores- más reciente (lo que parece implicar que se obvia "por moderna"), se utiliza sin embargo al momento siguiente como referente "de antigiedad", puesto que esa misma fecha de $c .1540 \mathrm{cal}$. ANE del yacimiento almeriense de Gatas -apoyada en la posición estratigráfica de las obtenidas para la Cuesta del Negro y en la presencia de cerámicas incisas e impresas en el Cerro de la Encina, al final del asentamiento argárico- es en definitiva la que lleva a Castro, Lull y Micó a la identificación de la presencia de las primeras cerámicas de Cogotas $I$ en el SE ya hacia mediados -finales del S. XVI cal. ANE-, lo que conlleva a su vez aceptar la temprana aparición de las cerámicas de tipo Cogotas I fuera de La Meseta y casi al mismo tiempo en el cuadrante suroriental de la Península que en el valle del Ebro.

Finalmente, cabe apuntar aquí que la datación del Caserio de Perales del Río, publicada con posterioridad al trabajo de Castro, Lull y Micó, no ha confirmado la hipótesis propuesta por los investigadores catalanes acerca de la posible ubicación temporal de las cerámicas de Cogotas I del valle del Tajo entre los siglos XVII y XV A.C., o lo que es lo mismo, entre las consideradas como las más antiguas cerámicas de ese tipo y las presumiblemente más recientes y correspondientes a su "expansión" extrameseteña, ya que dicha datación sitúa al yacimiento madrileño en \pm 1629 cal. B.C. (Blasco, Calle y Sánchez-Capilla, 1995).

Por último, merece también especial atención la utilización de las fechas de $c .1354$ cal. ANE y c. 1300 cal. ANE de Llanete de los Moros y Moncín, respectivamente, como indicativas del final de la segunda etapa identificada en el desarrollo de Cogotas I puesto que, al margen ahora de la ya comentada problemática situación estratigráfica de dichas fechas en los respectivos yacimientos, y al ser identificada la procedente del yacimiento cordobés como indicador de un cambio en el proceso cultural -la aparición de "relaciones" con el valie medio del Guadalquivir- la utilización de dicha fecha en este caso parece poner de manifiesto que los autores catalanes definitivamente excluyen del repertorio de dataciones "válidas" no sólo la de Setefilla, sino también las de Peñalosa, cuando, sin embargo y como se ha referido, en opinión de los propios autores, las del yacimiento jienense tal vez podrían indicar la existencia de relaciones entre La Meseta y el Valle del Guadalquivir en la etapa anterior.

Sobre la Fase 3: c. $1350-$ c. 1000 cal. ANE

Al hilo de los plantamientos precedentes, Castro, Lull y Mico proponen como "hechos arqueologicos" que caracterizarian a una tercera fase:

* la pervivencia durante ese lapso temporal (c. $1350-c .1000 \mathrm{cal}$. ANE) de la cerámicas tipo Cogotas I en los valles de los ríos Duero y Tajo y en el alto Ebro y 
- la aparición de las mismas en el valle del Guadalquivir y su perduración en esta zona hasta la última parte del s. XII A.C.

Los autores proponen la identificación y delimitación temporal de esta tercera fase argumentando en primer lugar que la pervivencia de las cerámicas de Cogotas $I$ en el alto Ebro hasta finales del II milenio A.C. está avalada por la fecha de la Paul de Arbigano ( $c$. 1114 cal. ANE), y en segundo lugar considerando que la perduración de la cerámica tipo Cogotas I en los valles del Duero y del Tajo hasta $c .1000$ cal. ANE, apoyada en las dataciones de varios yacimientos "... podría significar la implantación del estilo decorativo en el marco de la dinámica social de las comunidades del grupo meseteño de Cogotas I .." (op. cit.; 165).

Pues bien, evidentemente la larga pervivencia de tipos cerámicos de uso común es más fácilmente explicable que la de producciones cuyos rasgos formales y decorativos ponen de manifiesto su especial papel y significado, razón por la cual la perduración de las cerámicas de tipo Cogotas I en el alto Ebro hasta finales del II milenio a.C. puede interpretarse bien como resultado de una continuidad en las relaciones que dieron lugar a su aparición en el valle del gran río en la fase anterior, en cuyo caso habría que buscar una explicación para el hecho de que aguas abajo, a la altura de Moncín, esas relaciones se interrumpieran unos 200 años antes (c. $1310 \mathrm{cal}$. ANE), o bien por el contrario podrían interpretarse como el resultado de la asimilación de esos tipos cerámicos por parte de los pobladores de ese área geográfica más tardíamente que en otras zonas del propio valle del Ebro.

Por otra parte, la interpretación que Castro, Lull y Micó plantean para la pervivencia de las cerámicas de tipo Cogotas I en los valles del Duero y Tajo hasta $c .1000 \mathrm{cal}$. ANE, resulta algo sorprendente en tanto que implica suponer que estas cerámicas, cuya presencia se constata desde unos 500 años antes en un buen número de yacimientos de esas regiones, de diferentes características y cronología pero considerados por diversos investigadores como correspondientes a un mismo complejo cultural entre otros motivos por su utilización de esa peculiar vajilla, no fueron sin embargo elemento integrado en la "dinámica social", y en consecuencia elemento integrante de la "cultura material" de aquellas gentes hasta 500 años después de su existencia como protagonistas de la Edad del Bronce meseteña.

Y en otro orden de cosas, en cuanto a la "aparición" de las cerámicas tipo Cogotas I en el valle del Guadalquivir, los investigadores catalanes señalan una serie de aspectos que es obligado considerar detenidamente.

Castro, Lull y Micó apuntan que la concordancia de la desaparición de estas cerámicas en el SE, en función de la fecha de c. 1362 cal. ANE de Gatas, ("redondeada" a c. 1350 cal. ANE) con su aparición en el Valle del Guadalquivir, en base a la fecha de Llanete de Los Moros, y su perduración en la zona hasta el momento que indica la serie radiocarbonica del yacimiento cordobés ( $c$. 1345 - $1135 \mathrm{cal}$. ANE), sugiere la existencia de una inflexión a escala peninsular en torno a $1350 / 1300$ cal. ANE, a partir de la cual las relaciones de La Meseta con el SE cesaron y se reorientaron hacia el valle del Guadalquivir, coincidiendo con la aparición en ambas áreas de las primeras cerámicas a torno (Cuesta del Negro, Gatas, Llanete de los Moros, Carmona), al tiempo que permite considerar dicha 
fecha de c. 1350 cal. ANE como indicativa de una época de cambio, marcando una nueva "inflexión" que permite a su vez diferenciar dos fases recientes de Cogotas $I$, pues a partir de ese momento aparecen nuevos asentamientos como el de Ecce Homo.

Así mismo, y siempre según los autores catalanes, las fechas asociadas a la presencia en Llanete de los Moros de cerámica de tipo Cogotas I (c.1354 - c. 1135 cal. ANE) indican tambien, para el periodo comprendido entre ellas, "... las asociaciones entre cerámicas de tipo Cogotas I y determinadas producciones metálicas, en especial las fibulas de codo de tipo Huelva ..." (op. cit.; 165), del mismo modo que "Las dataciones de La Requejada fechan tales ítems en la Meseta entre c. 1200 y c. 1050 cal. ANE." (ídem; 165-166), cabiendo recordar en relación con todo ello lo ya apuntado acerca de los problemas que plantean, por una parte, la posición estratigráfica de las dataciones procedentes del yacimiento cordobés y por otra, la relación realmente existente entre las cerámicas de tipo Cogotas I y las dataciones relacionadas con la fibula de codo - ajuar del enterramiento fechado - procedentes del yacimiento vallisoletano.

Por último, y respecto ya al final de esa tercera y última fase identificada por Castro, Lull y Micó para Cogotas $I$, los autores señalan que:

- hay una clara continuidad de los asentamientos hasta c. 1000 cal. ANE, corroborada por el enterramiento de La Requejada;

- las fechas meseteñas del s. XI cal. ANE indican su fase final en su área de origen, no habiendo dataciones posteriores a $c .1000 \mathrm{cal}$. ANE;

- en el valle del Tajo, coincidiendo con la última fase (c. 1250 - $1000 \mathrm{cal}$. ANE) aparecen cerámicas grafitadas y pintadas (facies Pico Buitre / Ecce Homo II y Riosalido), apareciendo posteriormente esas cerámicas pintadas en el valle del Duero (Soto de Medinilla);

- "Por tanto de la información cronométrica se desprende que desde c. 1250/1100 cal. ANE dio comienzo una dinámica de diversificación regional en la que desapareció la homogeneidad estilística que había caracterizado hasta entonces a las cerámicas de Cogotas $I^{\prime \prime}$ (op.cit; 167), y que

- estos datos indican pues que el final de Cogotas I se solapa temporalmente en la Meseta con los comienzos de la Edad del Hierro, lo que supone la convivencia durante cierto tiempo de la población indígena con otra nueva: a lo largo del último cuarto del II milenio a.C., la tradición de Cogotas I podría haberse mantenido en el Duero medio o al menos en los rebordes montańosos del Sistema Central, hasta c. $900 / 800$ cal. ANE en asentamientos de tipo castreño (Cancho del Enamorao, Sanchorreja) en los que, como en el madrileño de la Fábrica de Ladrillos “... se impuso una decoración basada en la incrustación de pasta roja y amarilla en las decoraciones incisas -impresas- boquique, que podría considerarse característica de la fase final de Cogotas I." (op. cit.; 167).

En este sentido cabe comentar que en el caso de Cogotas I, la identificación de las cerámicas decoradas y de las fechas asociadas a ellas como indicadores culturales resulta problemática en sí, al no tratarse de producciones "en serie" ampliamente comercializadas, sino, como todo parece indicar, de productos con un carácter especial, derivado al menos en parte del hecho de que tanto sus formas como sus decoraciones fueron en su momen- 
to algo así como el soporte físico de las "señas de identidad" de quienes las tenían y utilizaban normalmente, porque formaban parte de su equipo material tradicional, y posiblemente derivado también, al menos en algunos casos, de su carácter de ítem de prestigio cuando su posesión fue el resultado de transacciones comerciales o de negociaciones e intercambios asociados a diferentes tipos de "relaciones humanas" (familiares, sociales, politicas).

Desde esta óptica, el hablar de "pervivencia" de las cerámicas de tipo Cogotas $I$, ya sea hasta finales del II milenio A.C. o hasta los comienzos del siguiente, tratando de detectar los acontecimientos de que, de alguna forma, es testimonio todo ello, implica plantear al menos dos posibles interpretaciones de los datos arqueológicos, interpretaciones que conllevan evidentemente diferentes maneras de reconstruir la Historia, deduciendo de esos datos o bien la perduración hasta esos momentos del complejo cultural que tuvo esas cerámicas como parte de su propio equipo material y que había representado la Edad del Bronce en la Submeseta Norte, aún cuando en su última etapa hubiese incorporado a su producción alfarera modos y modas decorativos "recién llegados" a la Península Ibérica en manos de inmigrantes culturalmente ya de la Edad del Hierro y de origen continental, o bien, y por el contrario, la pervivencia únicamente de esas producciones alfareras incluso en una época y entre unas gentes ya culturalmente diferentes y mucho más "modernas"

\section{DISTINTOS ENVESTIGADORES, DIFERENTES OPINIONES}

Pese a estar basada en datos tan objetivos como lo son las dataciones absolutas, la propuesta de datación y periodización del "fenómeno" Cogotas I de Castro, Lull y Micó en modo alguno encajaría en los marcos cronológicos propuestos también recientemente por otros investigadores (Tabla 3), entre los que cabe mencionar ahora en primer lugar el propuesto para la Edad del Bronce de la Península Ibérica por M. Almagro-Gorbea (1996), marco basado en la cronología relativa y en el que el autor sitúa el comienzo de la primera etapa de Cogotas 1 ("horizonte" Cogeces) poco antes de mediados del II milenio a.C., y el desarrollo de sus etapas plena y final desde un momento avanzado de la segunda mitad de ese mismo milenio hasta bien entrado el I milenio a.C..

Posiblemente las divergencias existentes entre las propuestas de los autores catalanes y las de M. Almagro-Gorbea y Maya y Mestres, respectivamente, pueden explicarse, al menos en parte, por la utilización de diferentes métodos de datación -los que proporcionan resultados "absolutos", los primeros, y los que plantean cronologías relativas, los segundos- ambos igualmente válidos como métodos arqueológicos pero que sin duda han de ser complementarios, lo que deja abierta una interesante vía de investigación y estudio en relación con la problemática de Cogotas $I$.

Ahora bien, esa "complicidad" entre la cronología absoluta y la relativa, que es de esperar dé respuesta en su día a muchas de las interrogantes que la Prehistoria tiene hoy planteadas, hay que buscarla y utilizarla con suma precaución, o de lo contrario puede dar lugar al planteamiento de hipótesis e interpretaciones difícilmente contrastables con la 


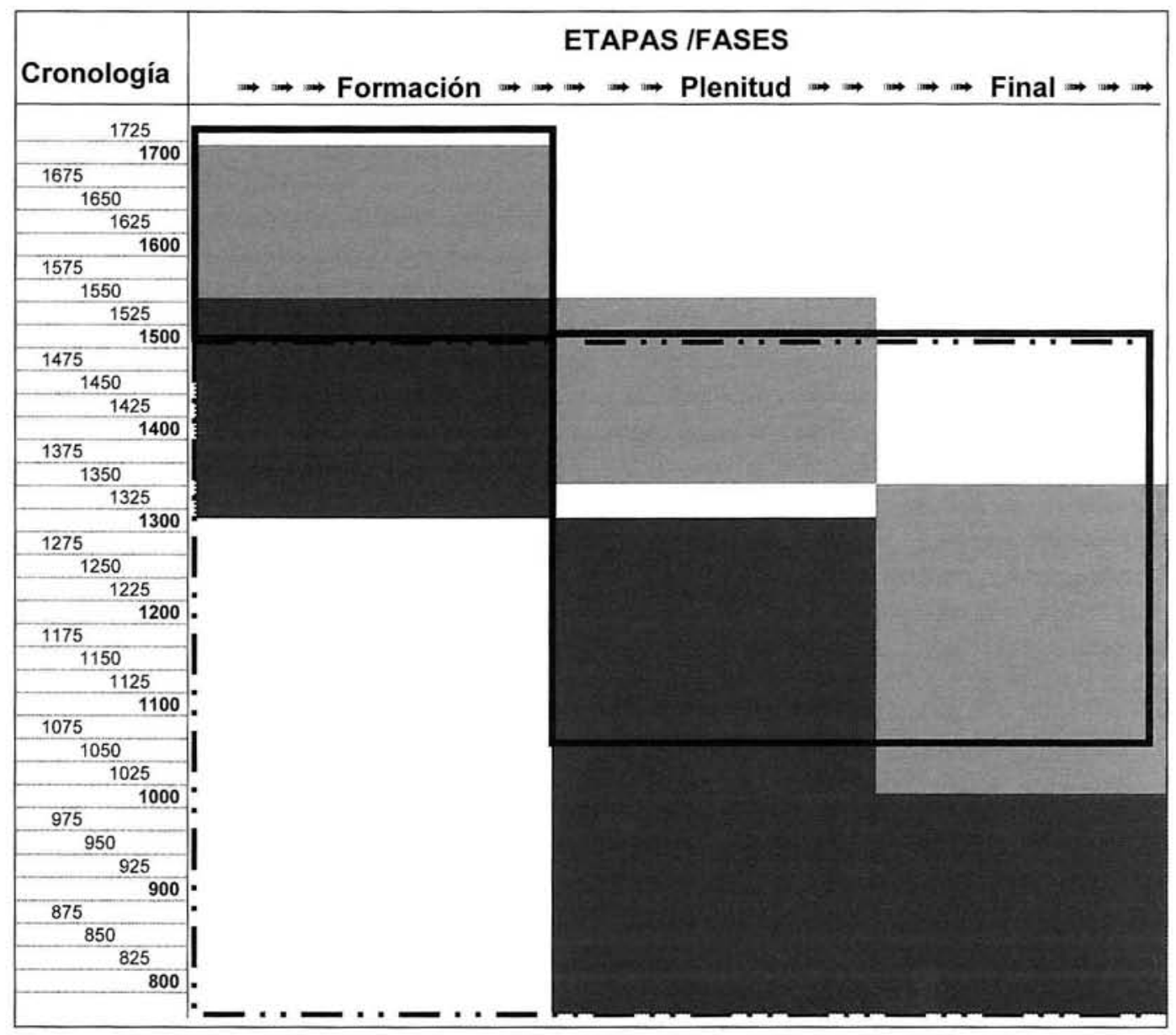

Tabla 3. Cronología de Cogotas I: según Castro, Lull y Micó, 1996; $\square$ según Almagro-Gorbea, 1996; [:] según Maya y Mestres, 1996; $\square$ según Blasco Bosqued, 1997.

documentación propiamente arqueológica, así como a "estados de la investigación" como el que es objeto de estas páginas, cuyo análisis permite observar posiciones encontradas entre quienes utilizan no sólo las dataciones obtenidas mediante la aplicación de técnicas no propiamente arqueológicas, como la radiometría, sino también las correcciones que esos resultados puedan sufrir a medida que esas técnicas se perfeccionan, y quienes optan por la utilización a ultranza de los conocidos como "métodos tradicionales de la Arqueología", sin que ello implique que en ese "estado de la investigación" no se observen también posturas que, al tratar de resolver el problema, plantean soluciones "conciliadoras", si bien no siempre de fácil comprensión. 
En este sentido, merece especial atención el ya también citado trabajo de $\mathbf{M}^{2} \mathrm{C}$. Blasco Bosqued (1997), en el que aparentemente se conjugan y aúnan los resultados de las dataciones absolutas relacionadas con Cogotas $I$ con las conclusiones a que ha llevado la cronología relativa a lo largo de los últimos años, aspecto al que hay que sumar el hecho de que, si como se apuntó en líneas anteriores, el trabajo de Castro, Lull y Mico (1996) no profundiza en el tema de la clasificación cultural de las etapas diferenciadas, sin embargo en el de $\mathrm{M}^{a}$ C. Blasco se postula claramente, como en el también antes aludido de $\mathrm{M}$. Almagro-Gorbea (1996), la clasificación cronocultural de los periodos identificados desde la aparición de Cogotas $I$ hasta los momentos marcados por las dataciones más recientes, pues, en palabras de la autora, "...el Horizonte Cogotas $I$ ha generado durante las tres últimas décadas una cantidad ingente de aportaciones, de difícil sistematización, que ha hecho posible su definitiva ubicación dentro de un amplio espacio temporal que cubre la segunda mitad del segundo milenio abarcando desde el Bronce Pleno al Bronce Final" (op. cit., pág. 61).

Al margen ahora del hecho de que la propia autora no parece querer ser demasiado tajante con esa afirmación, ya que en las primeras líneas de esa misma publicación señala la correspondencia de Cogotas $I$ a un Bronce Tardío y Final, es preciso sin embargo tener en cuenta otros aspectos del trabajo de $M^{*}$ C. Blasco que suponen argumentos diferentes a los utilizados por otros investigadores.

En el listado de dataciones relacionadas con la cerámica campaniforme, la autora omite las procedentes del nivel Ila de la Cueva de Arevalillo de Cega "... ya que las cerámicas campaniformes se asocian a las típicas de Cogotas 1." (op. cit., pág. 62, nota 2), lo cual supone desestimar totalmente una situación arqueológica que, como ya se ha señalado, puede ser interpretada de diferentes formas, pero no es discutible en tanto que parte de la directísima asociación no sólo de las respectivas "especies" cerámicas, sino también de la de las técnicas decorativas típicas de las producciones campaniforme y cogotas $I$ en un mismo vaso, máxime cuando además al ignorar todas las dataciones de Arevalillo se ignoran tambiến las claramente inmersas en el marco cronológico propuesto por la propia Dr Blasco (c. 1581 y c. 1576 cal ANE).

En otro punto y tras presentar un listado de dataciones absolutas (op. cit., Tabla 2) en el que, junto a las consideradas como válidas por Castro, Lull y Mic 6 , recoge la procedente de La Venta ( $c$. $1382 \mathrm{cal}$. ANE) -desestimada por los investigadores catalanes por proceder de un nivel de abandono (Castro, Lull y Micó, 1996, Apéndice VI) -las de El Balconcillo, Carrelasvegas y La Huelga- pese a no estar calibradas como las demás- y la de El Caserio de Perales, la autora, desestimando ahora las fechas de La Huelga por demasiado modernas, identifica un marco cronologico con las fechas de 1465 a.C. (1716 cal. ANE) y 1280 a.C. (1480 cal. ANE) para la etapa de formación de Cogotas I, aceptando al parecer esas dataciones calibradas puesto que señala el desarrollo de dicha etapa antes de mediados del II milenio a.C., pese a haber afirmado anteriormente que el Horizonte Cogotas $I$ se originó en las cuencas de los ríos Duero y Tajo desde mediados del II milenio (op. cit., pág. 75), y pese a referirse en páginas posteriores a un "...horizonte metalúrgico y cronológico de la segunda mitad del segundo milenio en el que se encuadraría el horizonte protocogotas ." (op. cit., pág. 82). 
Por otra parte, al comparar ese conjunto de dataciones con otras asociadas a un Bronce Pleno meseteño de diferente signo cultural (el caracterizado por cerámicas lisas), $M^{2}$. C. Blasco sugiere que tal vez ambas tradiciones pudieron existir sincrónicamente, al menos en algunas zonas ( $O$ P. cit., pág. 76), pero cabe señalar al respecto que los datos objetivos parecen indicar otra direccion.

Partiendo de la base de que, para que resulte válida, dicha comparación habrá de hacerse entre dataciones en las mismas "circunstancias" (en ambos casos sin calibrar o calibradas), y en base a los datos presentados por la propia autora, si las fechas calibradas asociadas a la etapa de formación de Cogotas I se hayan entre 1716 y $1480 \mathrm{cal}$. ANE, como ella misma propone, las también calibradas asociadas a ese "horizonte de cerámicas lisas" señalan un lapso temporal delimitado por las fechas $2442+100$ cal. ANE de El Tomillar y 1310 cal. ANE de las terrazas del Manzanares.

¿Cuâl es pues la relación entre las dataciones que marcan esos límites temporales, 2442 - $1716 \mathrm{cal}$. ANE y $1480-1310 \mathrm{cal}$. ANE? Curiosamente, esas fechas quedarian más próximas entre si -aunque es cierto que solo relativamente- utilizando en la comparación las dataciones calibradas para "protocogotas" y las no calibradas para el "horizonte de cerámicas lisas", pues ello daría dos lapsos temporales ubicados en 1716 - $1480 \mathrm{cal}$. ANE y 1975 - $1100 \mathrm{cal}$. ANE, respectivamente, lo que supondría aceptar la aparición de Cogotas $I$ cuando ya existía el "Horizonte Parpantique", pero entonces supondría también la reclasificación cronocultural de la primera etapa de Cogotas $I$, puesto que su paralelización con ese "Horizonte Parpantique" implicaría su correspondencia a un Bronce Antiguo o a un Bronce Pleno en cualquier caso muy temprano ...

Más delante, al referirse a la etapa de plenitud de Cogotas $I$, en la que identifica dos momentos, uno de plenitud y otro evolucionado aunque sin indicar el punto temporal en que se situaría la divisoria entre ambos, $M^{2}$.C. Blasco, tras señalar que una de las características de dicha etapa es la aparición de la decoración excisa en la cerámica, presenta una serie de dataciones que configurarian el marco temporal de esa fase (op. cit., Tabla 3) y en la que se observa:

- la exclusión de las fechas de 1676 y 1668 cal. ANE de Los Tolmos, correspondientes al mismo nivel II del yacimiento del que proceden las otras dos dataciones más recientes; es cierto que en el trabajo de Castro, Lull y Micó (1996, Apéndice VI) sólo se especifica la asociación de la fecha $1466 \mathrm{cal}$. ANE a cerámica excisa, pero también lo es que, como es sabido, ese tipo de cerámica está presente en todo el nivel II del yacimiento soriano, resultando además algo sorprendente que la autora, que en otros casos tiene muy en cuenta la opinión de los investigadores catalanes sobre la validez de ciertas dataciones, en éste considera válidas precisamente las dos (1466 y 1295 cal. ANE) de Los Tolmos que Castro, Lull y Micó excluyeron por su distanciamiento de la serie (op.cit., Apéndice VI).

- Así mismo, Blasco Bosqued excluye del conjunto de fechas representativas de ese segundo periodo de Cogotas $I$-conjunto en el que incluye algunas no calibradas - las del nivel III de El Portalón de Atapuerca "... por presentar cierta dispersión ..." (Blasco, 1997, pág. 86), con lo que , si por una parte no considera "operativas" ninguna de las dataciones del nivel III del yacimiento burgalés- y hay que recordar al respecto que Castro, Lull y Mico 
solamente desecharon la de 2034 cal. ANE por presentar una desviación típica muy elevada y una contextualización dudosa, como ya se indicó -, por otra parte parece estar negando de nuevo, como para el caso de Los Tolmos, la posibilidad de que ese nivel arqueológico contenga restos de una única etapa de larga duración que al parecer habría que situar en Atapuerca entre 1704 y $1017 \mathrm{cal}$. ANE.

- Respecto a la última etapa de Cogotas I en opinión de la autora el marco temporal que determinan las fechas absolutas abarca el lapso comprendido entre 1260 a.C. (1489) cal ANE) y 870 a.C. (1035 cal. ANE), coincidiendo con el Bronce Tardio y el Bronce Final I del SE, y "... las etapas finales son las que conocen la llegada al territorio nuclear de Cogotas $I$ de las fíbulas de codo de origen mediterráneo." (op. cit., pág. 86). Este planteamiento implica excluir de la serie la fecha más antigua de Tapado de Caldeira sin argumentar la causa, si bien al ser una datación procedente del nivel de base de la sepultura I (Castro, Lull y Micó, 1996, Apéndice VI), es posible que no corresponda a dicha sepultura sino al nivel arqueológico en que fue excavada su fosa -lo que explicaría la distancia entre ambas dataciones-, pero implica también asociar a dicha serie esos materiales metálicos que $\mathrm{M}^{\mathbf{a}}$ C. Blasco considera típicos de esta segunda etapa de Cogotas $I$-pese a no estar asociados a contextos de Cogotas I y a haber sido fechados por tipología- como hachas de talón con rebordes y anilla lateral, la espada de Guadalajara y espadas "de lengua de carpa" y puñales clasificados como correspondientes al Bronce Final III.

Y por último, cabe señalar también que de trabajos que utilizan los mismos puntos de apoyo cabría esperar propuestas con conclusiones muy semejantes, pero ante los de Castro, Lull y Micó y $\mathrm{M}^{a}$. C. Blasco no deja de sorprender el hecho de que haya sensibles discrepancias, tanto respecto a los límites cronológicos de Cogotas $I$ como a su periodización, tal y como se puede observar en la Tabla 3 que acompaña a estas páginas.

\section{UNA INTERPRETACION DIFERENTE}

Con todo, y pese a los problemas que nos plantea aceptarlas, no podemos negar lo atractivas que resultan las interpretaciones propuestas por Castro, Lull y Micó y por $\mathrm{M}^{2} \mathrm{C}$. Blasco respecto a un elemento tan representativo e interesante de la Edad del Bronce meseteña como son las cerámicas decoradas tipo Cogotas I, sin profundizar ahora en su relación con esas producciones metálicas a las que no están claramente asociadas y que, por su parte, constituyen el argumento básico en el que apoyan otros investigadores, como $\mathbf{M}$. Almagro-Gorbea, una clasificación cronocultural diferente para el complejo/"horizonte"/cultura conocido como Cogotas I. Ahora bien, desde otro punto de vista, es evidente que también resulta muy atractivo el intentar plantear otras hipótesis a partir del marco cronológico que prefiguran las dataciones calibradas actualmente disponibles.

Desde un punto de vista diferente, las fechas no soh sino un elemento más de información con el que el arqueólogo ha de contar, pero justamente para lo que sirven a la Arqueología es para situar en el tiempo los restos culturales, de tal modo que deben ser éstos, y no las propias fechas en sí, los puntos de apoyo de las interpretaciones que cual- 
quier investigador plantee respecto a los procesos histórico-culturales representados por el modo y lugar de la presencia de los mismos.

En honor a la verdad hay que admitir que las dataciones absolutas fechan "momentos $^{n}$, y que, en consecuencia, una serie de dataciones constituye una colección más o menos abundante de "momentos" cuya ubicación temporal nos es así más o menos exactamente conocida, pero hay que admitir también que en el caso objeto de este artículo, el conjunto de fechas absolutas que Castro, Lull y Micó han recogido como claramente relacionadas con contextos arqueológicos en los que están presentes las cerámicas tipo Cogotas $r$ plantea en sí mismo ciertos problemas en cuanto a su propia composición.

Así, de la observación de la propia Tabla 1 presentada (que recoge como se recordará las fechas consideradas "válidas" por los investigadores catalanes) se puede deducir que:

- la serie de dataciones procede de yacimientos localizados en áreas geográficas distintas y distantes, desde el País Vasco al valle del Guadalquivir y desde la Submeseta N a Portugal y el SE, pero

- en la mayoría de los casos cada yacimiento "representa" prácticamente a una zona, entendiendo aquí como tal la comprendida en los respectivos límites administrativos correspondientes a las actuales provincias de Jaén, Burgos, Zaragoza, Segovia, Sevilla, Ávila, Soria, Salamanca, Almería y, si a esa serie se suma la datación más recientemente conocida de Hoyas del Castillo, también Cuenca; las excepciones al respecto son los casos de las provincias de Palencia -de la que no podemos contabilizar la datación procedente de Carrelasvegas por no haber sido calibrada (Martín Carbajo, 1993; 81, nota 4)-, y Álava, de donde proceden de 2 yacimientos de cada una de ellas, y los casos también de Madrid -puesto que a los dos yacimientos recogidos por Castro Lull y Mico hemos de añadir ahora el del Caserío de Perales del Río-, Valladolid y el área portuguesa, que cuentan con 3 yacimientos con dataciones absolutas, respectivamente. El resuitado de ello es que

- hay igual número de yacimientos con fechas absolutas en la Meseta que para las distintas áreas periféricas, o lo que es lo mismo, mientras las fechas de 12 yacimientos pueden "representar" a la Meseta, sin embargo el bajo Duero y el Valle del Ebro, el SE y el valle del Guadalquivir estarian representados por 3, 3, 2 y 2 fechas respectivamente, lo que supone una representatividad cuantitativamente muy poco uniforme.

Por otra parte, el número de dataciones que componen la serie es relativamente elevado y cubre todas las centurias del II milenio A.C., pero mientras que de algunos yacimientos solamente hay una fecha, de otros hay varias, lo que dificulta la identificación de periodos, a menos que esas fechas únicas se consideren representativas de "momentos medios"; asi mismo hay que sumar a todo esto el hecho de que, por motivos a todas luces aleatorios, mientras para determinados periodos, como los siglos XVII, XVI, XV, XIV y XIII ANE, hay varias dataciones disponibles, sin embargo otras etapas están representadas por una sola fecha (segunda mitad del $s$. XX ANE, primera mitad de los siglos. XVIII y XII ANE) o incluso no lo están por ninguna, como es el caso de la segunda mitad del s. XIX y de la primera mitad del s. XI, evidentemente ANE en ambos casos. 
En consecuencia pues, si a lo comentado en páginas anteriores en relación con la problemática concreta de las dataciones obtenidas en determinados yacimientos se suma la problemática general que afecta al conjunto de fechas relacionado con Cogotas I, el panorama resultante sugiere dos opciones: obviar el aspecto cronológico en función de ese cúmulo de problemas, o bien intentar su análisis con un nuevo enfoque, es decir, observando esta serie de fechas primero como un conjunto de datos que, per se, no aportan más que la ubicación temporal de las muestras de que proceden, pero que evidentemente tienen alguna relación con los contextos arqueologicos asociados a ellas, y en segundo lugar tomándolas como indicadores temporales, y solamente eso, de un conjunto de acontecimientos con los que de alguna forma hay que relacionar estructuras, contextos y materiales arqueologicos.

\section{Dataciones, "inflexiones" y fases}

Teniendo en cuenta TODAS las dataciones recogidas por Castro, Lull y Micó, salvo las de $c$. 2080 y c. 2042 cal. ANE de Peñalosa, por las razones señaladas en su momento, y sumando a ellas las más recientemente publicadas del Caserío de Perales y Hoyas del Castillo puesto que evidentemente enriquecen la serie, ordenando el conjunto en sentido decreciente y manteniendo juntas las fechas correspondientes a un mismo yacimiento, tal y como queda reflejado en la Tabla 4, y así mismo partiendo de la base de que a priori todas ellas PUEDEN SER indicadores temporales válidos, entonces es posible observar que el marco cronológico que se perfila para el "fenómeno" Cogotas I, por una parte es sensiblemente diferente a los confeccionados por los autores mencionados en este trabajo, y por otra sugiere otra interpretación distinta, dejando abierta la posibilidad de que los acontecimientos sucediesen de otra forma, aunque planteando al mismo tiempo un buen número de incógnitas.

No obstante, es necesario también hacer hincapié en el hecho de que, hoy por hoy es evidente la relevancia que tienen las dataciones absolutas a la hora de reconstruir la Historia, y que, aunque la interpretación que ahora se propone de esos datos sea diferente de la planteada por Castro, Lull y Micó, incluso discrepante en diferentes aspectos, $\sin$ embargo la suya debe ser considerada como un buen exponente de los caminos metodologicos por los que actualmente debe discurrir la Arqueología Prehistórica, de tal forma que, aunque a quien suscribe estas páginas las dataciones absolutas calibradas le sugieran otras reflexiones, sin embargo es obligado reconocer que, como señalaron los investigadores catalanes, muy posiblemente la primera y más obvia conclusión que se desprende de la observación de la serie de dataciones absolutas relacionadas con Cogotas I, es la constatación de que su desarrollo no fue uniformemente continuo, sino que en él hubo determinados cambios, deducibles efectivamente de la existencia de ciertas "inflexiones" temporales identificables en la serie cronométrica, así como la constatación también de que muy posiblemente la primera de esas "inflexiones", la más antigua, algo debió tener que ver con la primera etapa del complejo cultural que nos ocupa, se denomine ésta Proto-Cogotas $I$ o no. 
Todo inclina pues a pensar que estos datos arqueologicos, es decir, las dataciones absolutas, a efectos de identificar una periodización deben considerarse más indicativos, en tanto que proceden de restos culturales, que la presencia/ausencia de determinadas decoraciones cerámicas, -y ésta es una opinión compartida evidentemente con varios investigadores-, y, desde luego, más indicativos que el resultado del análisis de la variabilidad espacial de unas producciones alfareras, resultado que, en cualquier caso, también habría que interpretar pero que $\mathrm{M}^{2}$ D. Fernández-Posse (1998) parece considerar como una base mucho más sólida para identificar fases y periodos que las dataciones absolutas calibradas, hipótesis que habria que matizar observando que si la presencia/ausencia de tipos decorativos no ha de interpretarse necesariamente como indicador temporal, tampoco ha de identificarse como tal su distribución espacial, puesto que en ambos casos esa presencia/ausencia puede deberse a otros factores de indole muy diversa, seguramente intimamente ligados a la propia razón de existir de esas cerámicas decoradas.

En función pues de todo lo dicho hasta aquí, parece oportuno exponer a continuación nuevos razonamientos e interpretaciones de las dataciones absolutas relacionadas con las cerámicas tipo Cogotas I, basados ahora en la constatación de que esas cerámicas aparecen en diferentes áreas geográficas, en asentamientos y enterramientos de distintas características y no asociadas siempre a los mismos materiales arqueologicos ni en los mismos tipos de contextos - de lo que se desprende la necesidad de analizar su variabilidad no sólo espacial, sino también de procedencia y contextual-, y también de que aparecen así mismo relacionadas de alguna forma con una serie de dataciones absolutas hoy "calibradas" y cuya variabilidad, que sí ha sido analizada e interpretada, impide aceptar algunos postulados enunciados por $\mathrm{M}^{2} \mathrm{D}$. Fernández-Posse, investigadora con la que, si bien es preciso convenir en admitir que si lo que se ha venido denominando "ProtoCogotas $I$ " fuese el pèriodo de formación, lo sería de un complejo cultural que estuvo formándose nada menos que cuatro siglos, no es necesario sin embargo compartir la opinión respecto a que las gehtes que tuvieron como propias las cerámicas tipo Cogotas I utilizaran siempre los mismos tipos de asentamientos y enterramientos ni el mismo modo de explotación del territorio, ni tampoco su afirmación de que "... el contenido arqueológico de lo que hoy se llama Protocogotas no indica que se esté gestando una sociedad, que sería Cogotas $I$, sino que se trata de la misma (...) Creo que puede empezar a descartarse esa división de la cultura en un periodo formativo de amplitud inusitada y un periodo pleno-final con pervivencias (...) Quizá debiera proponerse justamente lo contratio: un largo desarrollo inalterado y una etapa final donde los cambios son sustanciales ya que afectan a algo más que a los aspectos formales de su vajilla." (Fernández-Posse, 1998; păg. 96).

\section{Sobre una primera fase: \pm 2050 - $\pm 1700 \mathrm{cal}$. ANE $m$. (Tabla 6).}

Por lo que respecta a las dataciones más elevadas, las que marcarian la aparición de los más antiguos elementos característicos de Cogotas 1, ya se indic 6 anteriormente la falta de argumentos objetivos para desestimar la fecha de c. 2034 cal. ANE de El Portalón de Atapuerca, en tanto que corresponde al nivel III del yacimiento como otras consideradas válidas, como tampoco existen realmente para excluir la de $c .1920$ cal. ANE de Castelho Velho. 


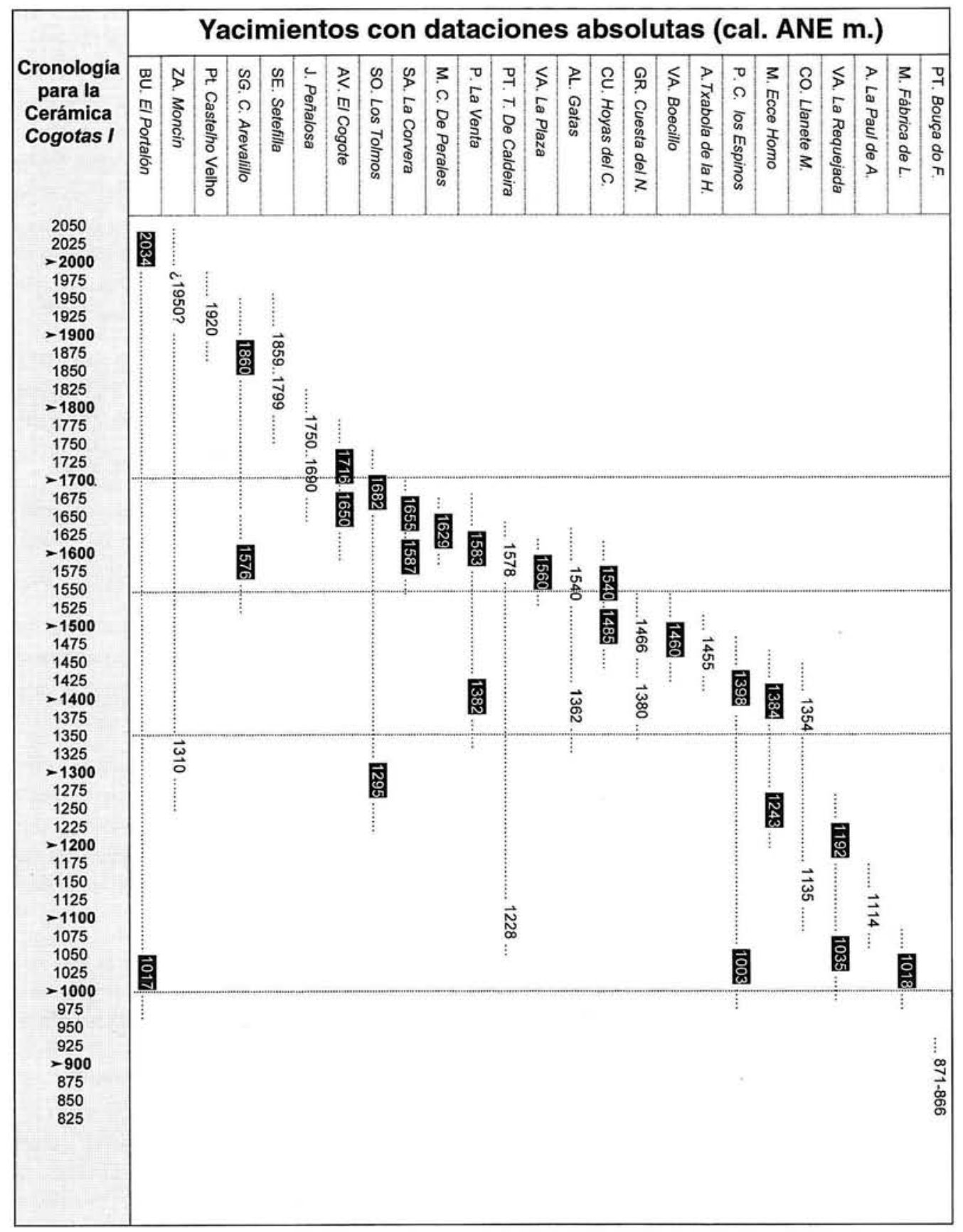

Tabla 4. Información tomada de Castro, Lull y Micó, 1996. (XXX : yacimientos meseteños) 
Por otra parte y respecto al yacimiento de Moncín, a lo ya comentado hay que añadir ahora que su excavador, que ya publico una serie de dataciones calibradas, señaló la aparición de cerámicas incisas junto a campaniformes "tipo Arbolín -circunstancia por tanto paralelizable con la del nivel IIa de la Cueva de Arevalillo- en la fase II D del yacimiento (Harrison, 1995 pág. 384 y ss.) fechada c. 1950-1700, así como la pervivencia del estilo cerámico Cogotas I c. 1700-1600 cal. ANE, la aparición del boquique en la fase II B, fechada c. 1600-1500 cal. ANE, y la de excisas en la fase II A, cuyo comienzo se sitúa en torno a 1500 cal. ANE. Ante este estado de cosas, que supone la existencia de opiniones encontradas entre distintos autores en cuanto a la calibracion de las dataciones y a la correspondencia de éstas a los distintos contextos y fases del yacimiento (Tabla 5), parece más prudente considerar el conjunto como s6lo ligeramente indicativo, y no sin reservas.

Desde esta perspectiva no son los yacimientos meseteños de Ávila, Soria y Salamanca (El Cogote, Los Tolmos y La Corvera) los de cronología más elevada, como proponen Castro, lull y Micó, sino el burgalés, geográficamente extrameseteño y próximo a la cabecera del Ebro, y los del Bajo Duero y Valle del Ebro, respectivamente, y es evidente que aceptar esto supone aceptar la presencia de cerámicas decoradas tipo Cogotas I en la periferia de La Meseta Norte con anterioridad a su aparición en su supuesta área de origen, y supone también aceptar que esa presencia se sitúa al final del último siglo del III milenio A.C. y en el transcurso del primer siglo del II, es decir, del s. XX cal. ANE.

Es obvio que este planteamiento deja en el aire varias incógnitas:

¿Es posible que los primeros elementos del "complejo" Cogotas I hagan su aparicion en las proximidades del alto Ebro y poco tiempo después se hallasen en el Ebro medio, llegando en poco más de un siglo hasta el bajo valle del Duero?

¿Es posible que ello fuera consecuencia de una primera llegada de "elementos" europeos en busca de territorios en los que asentarse, cuya "identidad" habrá quizá que deducir no sólo del uso de unas técnicas decorativas en algún caso ya conocidas en varios territorios peninsulares sino también de la aparición de determinadas formas cerámicas que representan una novedad en el repertorio de la alfarería entonces tradicional de esas áreas geográficas?

Una respuesta afirmativa a estas preguntas permitiria explicar la presencia de unos pocos fragmentos de esas cerámicas decoradas en contextos arqueologicos correspondientes a los últimos momentos del Bronce Antiguo, tal vez testimonios de la toma de contacto con la población indígena de unos inmigrantes en busca de tierras y presumiblemente con un equipo ligero y fácilmente transportable -en el que no necesariamente debería estar la cerámica decorada, puesto que si quien sabía fabricarla iba en el grupo podría elaborarla cuando fuese preciso-, tal vez testimonios de intercambios de "regalos entre jefes", como proponen algunos investigadores (Delibes,1995), y permitiría explicar también la constatación de este mismo autor de que es evidente que el estilo decorativo de la vajilla de Cogotas $I$, lejos de ser un unicum en el oeste de Europa, es uno más de los que trataron de imitar el grabado de la madera a punta de navaja (túmulos renanos, grupo de Fort Harrouard Videlles, etc.), afirmación que cobra más sentido si se piensa en la llegada a la Península de pequeños grupos ultrapirenaicos, pues de lo contrario habría que pensar en que algu- 


\begin{tabular}{|c|c|c|c|c|}
\hline Dataciones & Fase II D & Fase II C & Fase II B & Fase II A \\
\hline 2000 cal. ANE m. & & & 1986 & \\
1950 cal. ANE m. & & & 1952 & \\
1900 cal. ANE m. & & & & \\
1850 cal. ANE m. & & & & \\
1800 cal. ANE m. & & & & \\
1750 cal. ANE m. & & 1630 & 1590 & \\
1700 cal. ANE m. & 1648 & & 1581 \\
1650 cal. ANE m. & & & 1510 & \\
1600 cal. ANE m. & & & 1435 & \\
1550 cal. ANE m. & & & 1370 & \\
1500 cal. ANE m. & & & & 1332 \\
1450 cal. ANE m. & & & & \\
1400 cal. ANE m. & & & \\
1350 cal. ANE m. & & & \\
1300 cal. ANE m. & & &
\end{tabular}

Tabla 5. Moncín (Zaragoza): fases y dataciones radiocarbónicas cal. ANE. $\square$ Según Harrison, 1995. Según Castro, Llull y Micó, 1996.

nas gentes peninsulares traspasaron los Pirineos, conocieron los estilos decorativos y los plasmaron en sus producciones cerámicas a su regreso ...

Este argumento hace posible la aparición de elementos 'tipo Cogotas I' en el s. XX A.C. en áreas geográficas tan distantes como las que hoy pertenecen a Burgos, Zaragoza y Portugal, y si efectivamente ello estuvo en función de la movilidad de gentes que buscaban territorios en los que asentarse, entonces tanto parece perfectamente posible que desde el siglo siguiente, el XIX A.C., empiecen a "aparecer" yacimientos que de una u otra forma indiquen que "las novedades" habían producido su efecto y que, en consecuencia, "las cosas" empezaban a cambiar, como que, en función de esa misma movilidad, esas "nuevas" cerámicas decoradas empiecen a aparecer a su vez tanto en las áreas "intermedias" (Segovia) como en áreas más meridionales, incluso al sur del Tajo (Sevilla, Jaén).

$\mathrm{Al}$ hilo de este razonamiento, no habría entonces problema alguno en admitir que la cueva de Arevalillo, donde "la novedad" estaría representada básicamente por el resurgimiento de la decoración de boquique y la aparición de formas nuevas, sea uno de los muchos asentamientos que, desde la fecha más alta que ha proporcionado su nivel II a, $c$. 1860 XIX cal. ANE, fueron ocupando los territorios meseteños, asentamientos que, con una duración más o menos prolongada y con diferentes características, se fueron instalando y abandonando a lo largo de todo el II milenio A.C.. Así mismo, tampoco habría inconvenientes para aceptar la presencia de las cerámicas decoradas tipo Cogotas $I$ en el valle del Guadalquivir desde mediados del s. XIX cal. ANE (Setefilla) y en el S. XVIII A.C. (Peñalosa), lo que, de ser real, sugiere la posibilidad de que esta presencia sea indicativa bien de que la búsqueda de tierras en la que asentarse prosiguió por parte de pequeños grupos de inmigrantes que presuntamente seguirían llegando, pero que, al contrario que en La Meseta, no 
llegaron a instalarse en esa zona -porque tal vez no lo permitiera la existencia en ella de un complejo culural políticamente más potente y eficaz, el Bronce del Guadalquivir-, o lo que parece más posible, que sea indicativa de que para esas fechas las poblaciones meseteñas habían incorporado ya esas cerámicas decoradas a su elenco de productos de comercio y/o intercambio, hipótesis ésta coincidente con el planteamiento de $\mathrm{M}^{\mathbf{2}} \mathrm{C}$. Blasco al proponer que la presencia de cerámicas "protocogotas" en yacimientos meridionales "... quizá no haya que interpretarla como una irrupción de las gentes de la Meseta en regiones periféricas sino como signo de una continuidad de contactos ..." (1997, pág. 77).

\section{Sobre una segunda fase: $\pm \mathbf{1 7 0 0}- \pm \mathbf{1 5 5 0}$ cal . ANE $m$. (Tabla 6 ).}

Y siguiendo con los comentarios que sugiere la citada Tabla 3, hay que señalar ahora que la fecha de $c .1700 \mathrm{cal}$. ANE, que no necesariamente ha de considerarse como límite superior de la cronología del "Complejo" Cogotas I a tenor de lo expuesto en su momento, si parece marcar sin embargo el comienzo de la consolidación y desarrollo de "algo" que, a lo largo del s. XVII cal. ANE y durante los comienzos del s. XVI A.C. supuso la fundación, utilización y abandono, quizá una vez superada la situación de crisis que había dado lugar a su instalación, de algún asentamiento fortificado (Ei Cogote) y de otros ubicados tanto en lugares llanos como elevados, pero fundamentalmente en la cuenca alta y media del Duero (Los Tolmos en Soria, La Corvera en Salamanca) y, al sur del Sistema Central, en las tierras regadas por las aguas de la cuenca del Tajo (Caserio de Perales en Madrid).

$Y$ en el desarrollo de ese "algo", que bien pudo ser uno más de los Complejos Culturales que caracterizan la Edad del Bronce de la Peninsula Ibérica, a juzgar no tanto por las dataciones en sí sino por lo que estas pueden representar, todo parece indicar que al final del primer cuarto del s. XVI A.C., es decir, algo antes de $c .1575$ cal. ANE, algún acontecimiento, o varios, provocó o provocaron ciertos cambios con los que tal vez haya que relacionar:

- el abandono de la cueva de Arevalillo, pues la fecha de c. 1576 cal. ANE procede de cereal abandonado en el interior de un silo, y quizá el de otros asentamientos como el de La Corvera si la fecha $c .1587$ cal. ANE corresponde a la última etapa de ocupación del lugar;

- la fundación y desarrollo de otros como el palentino de La Venta, en el área central de la cuenca del Duero, mientras otros, como el de Los Tolmos, siguieron utilizándose;

- la aparición de las cerámicas tipo Cogotas I en el bajo Duero coincidiendo con el comienzo de una etapa en la que determinadas zonas de algunos asentamientos antes utilizadas como áreas de habitación, comienzan a utilizarse como áreas funerarias, ya corresponda la fecha de $c .1578 \mathrm{cal}$. ANE de Tapado de Caldeira a las tierras en que se excavó la sepultura de la que procede, o a la propia Sepultura I del yacimiento.

Sí los hechos se sucedieron realmente así, y si se relaciona la aparición de las cerámicas decoradas tipo Cogotas I con el comienzo en Ia Meseta de una etapa diferente al Bronce Antiguo, y por tanto con el comienzo del Bronce Pleno, entonces tal vez sea nece- 
sario plantear la posibilidad de que el proceso tuviese lugar en las dos etapas sugeridas, la primera (c. 2000 - c. 1700 cal . ANE), cronológicamente situada desde finales del III milenio A.C. y durante algo más del primer cuarto del II, correspondiente al comienzo del "cambio" y en la que tendría lugar la gestacion o formación de un nuevo complejo cultural, y una segunda etapa (c. $1700-c .1575 \mathrm{cal}$. ANE) que llegaria hasta un poco antes de la mitad de ese II milenio A.C. y que correspondería al desarrollo de lo que para entonces ya era ese nuevo Complejo Cultural sensu stricto.

Y si esa segunda etapa ya no corresponde a la formación sino al desarrollo de ese nuevo complejo cultural, zes posible que en ese desarrollo influyera un nuevo impulso relacionado de alguna forma con la aparición y difusión de las cerámicas excisas a mediados del II milenio A.C.?, jrepresenta la aparición de este nuevo modelo decorativo la llegada de nuevos inmigrantes y su incorporación al complejo cultural ya formado?, ¿puede ser esa la causa de que la cerámica excisa aparezca en el valle del Ebro (Moncín) antes que en La Meseta (c. 1550 cal. ANE en Moncín, c 1466 cal. ANE en Los Tolmos, ya al otro lado del "gran río")?

Desde esta óptica, efectivamente se observa esa "inflexión" cronológica a que se refieren Castro, Lull y Micó en torno a c. $1550 \mathrm{cal}$. ANE, y parece lógico compartir con los autores la idea de que esa fecha bien podría marcar el comienzo de una fase de plenitud del complejo cultural meseteño, fase con la que bien podrían asociarse varios "fenómenos" que bien pudieron ser a su vez consecuencias de ese apogeo.

Si un complejo cultural está suficientemente formado y consolidado, por una parte es foco de atracción, por otra tiene capacidad de acoger y absorber al menos a un pequeno contingente de inmigrantes, máxime si éstos son "parientes más o menos lejanos" de otros llegados anteriormente y por tanto no resultan elementos totalmente desconocidos.

Pues bien, algo así pudo suceder en el caso de Cogotas I, y ello explicaría hechos como la incorporación de nuevos modelos decorados a una vajilla "de lujo", o al menos de uso especial, cada vez más abundante y variada, la fundación de nuevos asentamientos y la ampliación de la red de relaciones, muy posiblemente sobre todo comerciales, de cualquier forma, sin que hablar de relaciones comerciales suponga rechazar la posibilidad por una parte de que, en función de las mismas, efectivamente se produjese un "intercambio de regalos" entre las partes implicadas, en cuyo caso las cerámicas decoradas tipo Cogotas I serían más símbolos que objetos de comercio per se, y por otra de que ese comercio, sus rutas y su frecuencia estuviesen muy íntimamente ligadas a los desplazamientos propios de ciertas actividades pastoriles, pues, pese a que algunos investigadores se han manifestado en contra del establecimiento de paralelos entre las rutas de trashumancia medieval y las prehistóricas (Fernández-Posse, 1998), e incluso han planteado to innecesario de esos movimientos en la Edad del Bronce argumentando la existencia de pastos naturales sufi" cientes en la cuenca del Duero y una supuestamente generalizada dirección Sur-Norte en la trashumancia peninsular, sin embargo no se pueden obviar los datos proporcionados por recientes investigaciones que confirman el traslado de ganado desde Soria a Sierra Morena durante esa Edad del Bronce peninsular, y por tanto hacia el sur 
Esta nueva hipótesis explicaria pues que aproximadamente desde mediados del s. XVI cal. ANE, en el área más "propia" de ese complejo cultural, en su "territorio institucional":

- poco a poco apareciesen nuevos asentamientos, algunos fortificados (La Plaza, Boecillo) precisamente en la zona que realmente debe denominarse "nuclear", la cuenca media del Duero, en tanto que su territorio era "propiedad" de esas gentes desde hacía ya mucho tiempo, y otros en territorios algo más periféricos (Hoyas del Castillo en Pajaroncillo, Cuenca), y que junto a todo ello

- aparezcan nuevas formas cerámicas, posiblemente como resultado tanto de cierta "evolución" de las típicas como de la "llegada" de algunas diferentes, asi como que

- aparezcan las decoraciones excisas junto a las entonces ya tradicionales incisas y de boquique, $y$

- que fueran estas últimas, las que representaban realmente la alfarería tradicional y típica de Cogotas $I$, y no las que suponen una "novedad" (las excisas), las que se "expor" tasen".

Estos planteamientos, y concretamente el expuesto en último lugar, explicaria también la aparición de incisas y boquique en el Sureste (Gatas en Almeria, Cuesta del Negro en Granada) como consecuencia del establecimiento de una relación comercial, o al menos de un intento de ello, relación antes -es decir, cuando el complejo cultural argárico estaba en su apogeo-, inexistente pero ahora posible si se admite que el auge de la población meseteña coincidió con la decadencia del grupo de El Argar, decadencia que a su vez pudo permitir en algún caso incluso la instalacion de un pequeño grupo de gentes meseteñas en algún asentamiento argárico, tal y como en su momento planteo $\mathrm{F}$. Molina para el caso de Purullena (Molina González, 1978). En este sentido es preciso recordar que, de acuerdo con las propuestas más recientes, todo parece indicar que c. 1550 cal. ANE El Argar había entrado ya en su fase terminal (Castro, Lull y Mico, op.cit.) o que al menos no se encontraba ya en su mejor momento, y también que, sin embargo en torno a esas fechas el Bronce de La Mancha era aún un importante complejo cultural (Sánchez Meseguer y Galán, 2001) en cuyo seno se habían producido relevantes cambios de los que difícilmente se puede deducir que reflejen ni siquiera inicios de decadencia cultural, tales como los que se plasmaron en la construcción de edificios de carácter religioso o en la amortización de armas metálicas o vajilla de uso específico en los ajuares funerarios, pudiendo muy bien haber tenido a mediados del II milenio A.C. un grado de desarrollo político y socioeconómico capaz de impedir la entrada en su mercado de productos meseteños, fuesen éstos solamente las cerámicas decoradas tipo Cogotas $I$ o también otros a los que éstas "acompañaban" de alguna forma, lo que explicaría a su vez la esporádica aparición de dichas cerámicas en la Mancha, paso obligado hacia el Sureste.

Y por último cabe señalar que este enfoque de la reconstrucción de los hechos explicaría también que en esa "apertura de mercados" desde el centro de la Meseta, incisas y boquique aparezcan en el alto Ebro (Txabola de la Hechicera) como indicio de unas relaciones que al parecer duraron, con mayor o menor intensidad, hasta comienzos del s. XII A.C. (La Paul de Arbignano). 
Sobre una tercera fase: $\pm 1550- \pm 625$ cal. ANE $m$.

Si parece evidente la "inflexión cronológica" que señalan Castro, Lull y Micó en torno a $1550 \mathrm{cal}$. ANE, aunque la interpretación propuesta para este hecho sea algo diferente de la que ofrecen los autores catalanes, también resulta claramente aceptable la existencia de otra "inflexion" señalada por los mismos investigadores en torno a $1350 \mathrm{cal}$. ANE, fecha en la que, a la vista de la Tabla 3, se detecta:

- que continúan algunos asentamientos como el de Los Tolmos;

- que otros, como la Venta, se habian abandonado algo antes y "paralelamente" a la fundación de

- otros asentamientos que, sobre esa fecha, están en plena vigencia, como los de la Cueva de los Espinos o el del Ecce Homo;

- que ya se había interrumpido la "llegada" de cerámicas decoradas tipo Cogotas I al Sureste (Gatas, Cuesta del Negro) y poco después al Valle del Ebro (Moncín), mientras que, sin embargo,

- a partir de esa fecha aparecen dichas cerámicas en el valle medio del Guadalquivir (Llanete de los Moros).

A la vista de este panorama resulta bastante obvio tanto la observación de que "algo" debió suceder a mediados del s. XIV A.C., como de que, fuese lo que fuese, ese "algo" provocó una serie de cambios en la dinámica del complejo cultural normeseteño, si bien es cierto que no resulta fácil interpretarlos porque todo parece indicar no que dejase de "funcionar" su sistema sino más bien que éste se modificó y siguió "funcionando" de orra manera.

Que tanto algunos asentamientos para entonces ya antiguos como otros de fundación mâs reciente seguían plenamente vigentes en torno a esa fecha de c. 1350 cal. ANE, y que esa circunstancia se daba en emplazamientos de diferentes ubicación y caracteristicas, son evidencias atestiguadas por las dataciones del poblado en altura de Los Tolmos (Soria), la Cueva del Espino (Palencia) y el "campo de hoyos" del Ecce Homo (Madrid), respectivamente, y ello podría indicar simplemente que el modo de vida, en el sentido más amplio del término, de los usuarios de las cerámicas tipo Cogotas I había cristalizado en una serie de mecanismos capaces de mantener la estabilidad del correspondiente complejo cultural. Pero junto a esto, también es evidente que no se detecta esa continuidad en todos los asentamientos de los que hay dataciones absolutas disponibles, hecho éste que lleva directamente a indagar cual fue la causa de que en la primera mitad del s. XIV A.C. mientras a unos les "iban tan bien las cosas", otros sin embargo se vieron obligados a abandonar sus asentamientos, como al parecer fue el caso de los ocupantes del palentino de La Venta, si bien es cierto que, como parece desprenderse de la serie de dataciones absolutas, para aquellas gentes meseteñas esa dinámica no era demasiado nueva.

Por otra parte también es claro que esas mismas dataciones ponen de manifiesto que poco antes de $c .1350 \mathrm{cal}$. ANE ceso la presencia de esas peculiares cerámicas decoradas en el SE (Gatas: c. 1362 cal. ANE; Cuesta del Negro: c. 1380 cal. ANE) y que casi inmedia- 
tamente después de ese cese comenzó su aparición en el valle medio del Guadalquivir (Llanete de los Moros: $c .1354 \mathrm{cal}$. ANE), aunque para alguna investigadora esta afirmación esté próxima a la especulación (Fernández-Posse, 1998), como también parece bastante lógico pensar que tanto estos hechos, que hoy por hoy habrán de considerarse arqueológicamente constatados en tanto no sea la propia investigación arqueológica la que demuestre otros, como los antes señalados en relación con los asentamientos, muy probablemente fueron los resultados de una nueva crisis que, en principio, no parece haber tenido su origen en el seno de Cogotas $l$, es decir, que no parece haber sido consecuencia de problemas internos ya que no se observa una reocupación de los antiguos asentamientos con alto valor estratégico -en sentido defensivo- ni la fundación de otros con similares características, 0 , lo que es lo mismo, no se detecta intención alguna de "fortificacion"

En este sentido todo apunta más bien a que muy posiblemente los cambios que se produjeron en la Meseta fueron el reflejo de una crisis pero extrameseteña, concretamente la sufrida por las poblaciones asentadas en el SE peninsular que, poco a poco y con el paso de los años, fue cristalizando en lo que se ha venido denominando Bronce Tardío y Bronce Final de esa área geográfica, términos que hoy se asignan a unos complejos culturales cuyas características ponen de manifiesto los fuertes cambios que habían tenido lugar respecto a la época anterior, la de la cultura argárica, y en cuyo seno se produjeron espectaculares "novedades" como la aparición de las primeras cerámicas fabricadas a torno, y cuya relación con el complejo cultural meseteño fue a todas luces muy diferente de lo que había sido la de sus predecesores del Bronce Pleno.

Y vistas así las cosas, nada impide pensar por una parte que los cambios en el SE repercutieran de cierta forma en la dinámica de aquellas poblaciones de alguna manera relacionadas con los habitantes de esa zona -ya fuesen los grupos que ocupaban el Levante, La Mancha o las tierras situadas al Norte del Tajo-, y por otra que la "reorientación" de relaciones comerciales hacia el valle medio del Guadalquivir a que se refieren Castro, Lull y Mico (1996) y el mantenimiento de las establecidas con los pobladores del valle del Ebro hasta finales del s. XIV A.C. (Moncín: $c .1310$ cal. ANE) e incluso hasta finales del s. XII A.C. (La Paul de Arbignano: $c$. 1114 cal. ANE), si realmente la relación fechas - acontecimientos es la propuesta, son datos que ponen de manifiesto la gran "vitalidad" de un complejo cultural que en un determinado momento modificó su modelo de ocupación territorial abandonando asentamientos que seguramente ya no cumplían una función necesaria para el sistema, manteniendo otros evidentemente útiles, instalando otros en las zonas tradicionales y también ocupando intensamente áreas que "ahora" resultaban especialmente "interesantes" como la Región Centro (valles del Tajo, Manzanares, Henares).

Es más, en la misma línea de razonamiento nada impide plantear que muy posiblemente en el último cuarto del II milenio A.C. (entre c. 1300/1200 cal. ANE y c. $1000 \mathrm{cal}$. ANE), el complejo cultural que ocupaba buena parte de las tierras castellanas "entró" en una etapa cronologicamente paralela al Bronce Tardío-Final de otras áreas pero culturalmente muy diferente, etapa en la que sus gentes, tradicionalmente conservadoras, apenas cambiaron su modo de vida, desplazando tal vez su "centro neurálgico" hacia el sur, a la Región Centro, pero siempre con el Tajo como límite de su territorio "propio" -recordemos que ese mismo río bien pudo serlo, por el norte, para las gentes del Bronce de la Mancha-, 


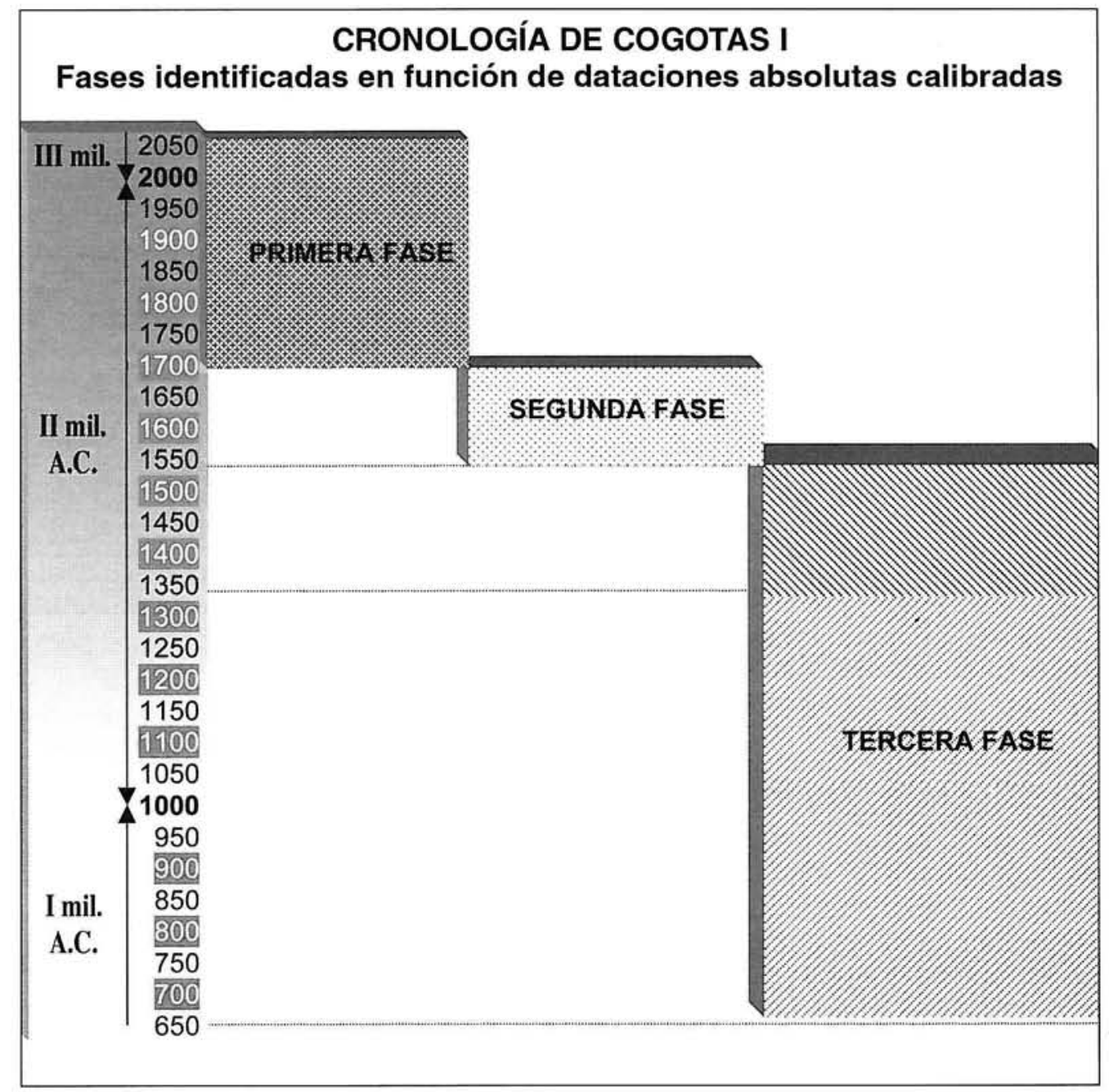

Tabla 6. Cronología propuesta para Cogotas I en función de las dataciones radiocarbónicas calibradas disponibles.

pero manteniendo sus relaciones, más o menos intensas, más o menos periódicas, con quienes venían intercambiando desde mucho tiempo atrás sus cerámicas decoradas y mientras éstas siguieron siendo apreciadas por otras gentes.

Si esta hipótesis se aproxima a la realidad de lo que sucedió, permitiría explicar el hecho de que siguieran "exportándose" las cerámicas tipo Cogotas I a otras áreas peninsulares -y bien puede estar relacionada con esa "exportación" la presencia en la Meseta de fíbulas de tipología mediterránea ("de codo" en La Requejada, ad occio en Caserío de Perales) y de ejemplares metálicos del Bronce Atlántico-, hasta los distintos momentos en 
que en cada una de ellas se fueron produciendo los acontecimientos que dieron lugar a su "paso" al Bronce Final o a la Edad del Hierro, según los casos. O dicho de otra forma, esta hipótesis permitiría explicar que siguieran llegando esas cerámicas decoradas al valle medio del Guadalquivir y al alto Ebro hasta el s. XII A.C. como parecen testimoniar las fechas de Llanete de los Moros (c. 1135 cal. ANE) y La Paul de Arbignano (c. 1114 cal. ANE), hasta momentos relacionados ya con el llamado Periodo Orientalizante y con la llegada de las gentes de los Campos de Umas, respectivamente, $y$ al bajo Duero incluso hasta bien entrado el I milenio A.C. (Bouça do Frade: c. $871 \mathrm{cal}$. ANE), pues nada impide pensar que, aun cuando la utilización de incrustaciones policromas indique el contacto de los fabricantes de las cerámicas decoradas tipo Cogotas I con las gentes de la Edad del Hierro llegadas al área central de la Submeseta Norte antes de $c 1000$ A.C., sin embargo algunos grupos "periféricos" siguieran fabricando su repertorio tradicional, lo que explicaría a su vez las tardías dataciones obtenidas en el yacimiento madrileño de la Fábrica de Ladrillos de Getafe ( $c$. 1018 y c. 618 cal. ANE).

Y para terminar. Estas páginas pretenden investigar la ubicación en el tiempo de una importante parte de la Prehistoria Reciente peninsular y recogen una propuesta, representada en la Tabla 6 y a modo de hipótesis a confirmar o rebatir en el futuro, de reconstrucción del marco temporal en el que al parecer surgio, se desarrolló y se extinguio el "fenómeno" cultural que hoy conocemos como Cogotas 1 : esperemos que el tiempo permita conocerle mejor, ya que presumiblemente él dirá quien tenía razón ...

\section{BIBLIOGRAFIA}

ALARÇAO, J. de (coord.), 1990: Portugal dos origens à Romanizaçao. Nova Historia de Portugal, I. Ed. Presença. Lisboa.

ALMAGRO-GORBEA, M., 1996: "L'Etá del Bronzo in Iberia: Cronología relativa", en Absolute Crhonology. Archaeological Europe 2500 - 500 BC. Acta Arcbaeologica, 67 Copenague, págs. 153-163.

BLASCO BOSQUED, $M^{2} C$., 1997: "La Edad del Bronce en el interior peninsular. Una aproximación al II milenio A.C. en las cuencas de los ríos Duero y Tajo" CuPAUAM, 24, págs. 59-100.

BLASCO BOSQUED, $M^{a}$ C., CAILE PARDO J. y SÁNCHEZ-CAPILLA, $M^{a}$ L., 1995: "Fecha de C-14 de la fase protocogotas I del yacimiento del Caserio de Perales del Rion CuPAUAM, 22, págs. 83-100.

CASTRO, P.V., LULL,V. Y MICO,R, 1996: Cronología de la Prehistoria Reciente de la Península Ibérica y Baleares (c. $2800-900 \mathrm{cal}$ ANE). BAR International Series, 652.Oxford. England.

DELIBES DE CASTRO,G., FERNÁNDEZ MANZANO J. y RODRÍGUEZ MARCOS, J.A., 1990: "Cerámica de plenizud Cogotas I: El yacimiento de San Román de Hornija. (Valladolid)" $B S A A$, LVI, pág. 64 y ss. 
DELIBES DE CASTRO, G., ROMERO CARNICERO, F Y MORALES MUÑIZ, A. (eds.), 1995: "Panorama arqueológico de la Edad del Hierro en el Duero Medio", en Arqueologia y Medio Ambiente. El Primer Milenio A.C. en el Duero Medio. Junta de Castilla y León. Consejería de Cultura y Turismo. Valladolid. Pág. 47 y ss.

EIROA, J.J., 2000: Nociones de Prebistoria General. Ed. Ariel, S.A., col. Ariel Prehistoria. Barcelona.

FERNÁNDEZ-POSSE, M² D., 1981: "La cueva de Arevalillo de Cega (Segovia)" $N A H, 12$, págs. 43-84.

FERNÁNDEZ-POSSE, M ${ }^{a}$ D., 1998: La investigactón protobistórica en La Meseta y Galicia. Arqueología Prehistorica, 1. Ed. Síntesis. Madrid.

GALÁN SAULNIER, C. y HERNANDO GRANDE, A., 1997: "La Edad del Bronce en la Meseta, hoy". Espacio, Tiempo y Forma, Serie I, 10, págs. 317-323.

HARRISON, R.J., 1995: "Bronze Age expansion 1750-1250 BC: The Cogotas I phase in the middle Ebro valley" Veleta, 12, págs. 67-77

MARTIN CARBAJO, M.A. y otros, 1993: "Documento funerario del Bronce Medio en la Submeseta Norte: "Carrelasvegas" (Santillana de Campos, Palencia)" BSAA, LIX, pág. 69 y ss.

MAYA.J.L. y MESTRES, J.S., 1996: "Approche à la chronologie de l'âge du Bronce et le premier âge du Fer dans la Péninsule Ibérique", en Absolute Crhonology. Archaeological Europe 2500-500 BC. Acta Arcbaeologica, 67 Copenague, págs. 251-269.

MOLINA GONZÁLEZ, F, 1978: "Definición y sistematización del Bronce Tardío y Final en el Sudeste de la Península Iberica"r CPUG, 3, págs. 159 - 232.

MOURE ROMANILLO, A. y SANTOS YANGUAS, J., 1999: Historia de España, 1 Prebistoria y primeras civilizactones. Ed. Espasa Calpe S.A. Madrid.

PEREIRA SIESO, J., 1994: "La transición del Bronce Final al Hierro en la Meseta Sur", en La Edad del Bronce en Castilla-La Mancba. Diputación Provincial de Toledo. Pág. 37 y ss.

SÁNCHEZ MESEGUER, J.L, y GALÁN SALINIER, C., 2001.: "Restos, huellas, evidencias.... Complejos de culto en el Cerro de La Encantada" Studien in Memoriam Wilbem Sbüle. Internationale Archäologie: Studia Honoraria; Bd. 11 pags. 379-417

ULREICH,H., NEGRETE, M" A. y PUCH, E., 1994: "Cerámica decorada de Hoyas del Castillo (Pajaroncillo, Cuenca). Corte $4^{n}$ BSAA, LX, págs, 105-135. 